\title{
Slam loads and pressures acting on high-speed wave-piercing catamarans in regular waves
}

Babak Shabani ${ }^{\text {a, }}$, Jason Lavroff ${ }^{\text {a }}$, Michael R Davis ${ }^{\text {a }}$, Damien S Holloway a and Giles A Thomas ${ }^{b}$

${ }^{a}$ School of Engineering, University of Tasmania, Private Bag 65, Hobart, Tasmania, Australia 7001.

${ }^{\mathrm{b}}$ Department of Mechanical Engineering, University College London, England, United Kingdom

* Corresponding author: Email address: babak.shabani@utas.edu.au

Declarations of interest: none

\begin{abstract}
Slamming loads and pressures on high-speed catamarans with a centre bow (CB) differ from those on conventional catamarans with flat deck structures. The latter are well covered by class rules, which provide empirical formulae to calculate the design slamming pressure. An experimental study was therefore performed to quantify slamming pressures in the archways between bow and main hulls and the CB slamming force on a $112 \mathrm{~m}$ wave piercing catamaran. The CB length was systematically varied on a $2.5 \mathrm{~m}$ hydroelastic segmented catamaran model, which was tested in regular head sea waves at a speed of $2.89 \mathrm{~m} / \mathrm{s}$, full-scale equivalent of 38 knots.

Slamming pressures were measured by 18 pressure transducers fitted into the $\mathrm{CB}$, while data obtained from $\mathrm{CB}$ accelerometers and load cells enabled identification of the slamming force. The results indicate that slamming loads increase significantly with increasing CB length while the maximum peak slamming pressures varies to a lesser extent. It was also found that wave encounter frequency has a strong effect on the location of maximum pressure along the $\mathrm{CB}$, considerably more so than any influence of $\mathrm{CB}$ configuration. The distribution of the peak pressures within the $\mathrm{CB}$ archway shows that the inboard peak pressures are larger than those at the top of the arch and the outboard locations.
\end{abstract}

Key words: wave piercing catamaran; hydroelastic segmented model; center bow; slamming load; slamming pressure

\section{Introduction}

The centre bow (CB) is important in wave piercing catamarans (WPCs) because it provides reserve buoyancy in the forward area when the vessel pitches strongly into incident waves, providing a substantial pitch restoring moment that mitigates against deck diving. However, in moderate and rough seas, CB entry is often associated with wet-deck slamming and may lead to large structural loads and vibration (whipping) [1-4]. Figure 1 shows the centre bow of a $112 \mathrm{~m}$ Incat catamaran, extending forward from approximately $76 \%$ of length from transom, 
creating archways between the CB and demihulls. Besides the influence of factors such as forward speed, wave height and relative impact velocity, the CB and archway geometry, depending on the design, can significantly affect the severity of slamming loads acting on the cross-deck structure between the demihulls and the CB [5-7].

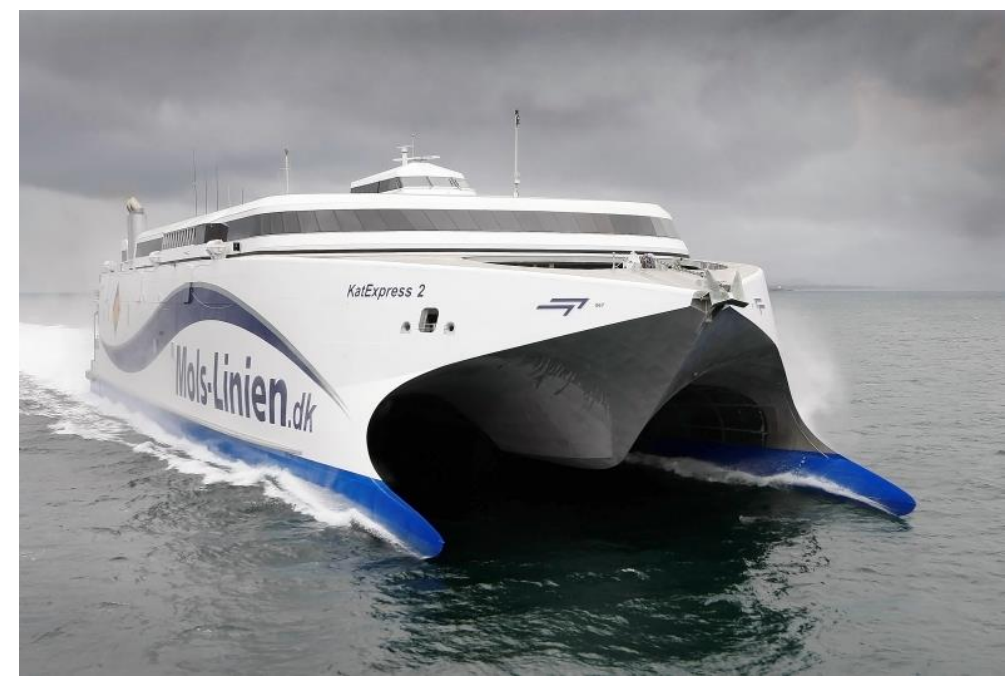

Figure 1 Incat Tasmania wave piercer catamaran with above-water centre bow (http://www.incat.com.au/)

Various techniques can be deployed to investigate wet-deck slamming in WPCs. For general ship slamming many are reviewed by Kapsenberg [8] and Hirdaris et al. [9]. In WPCs experimental techniques have been used extensively for the identification of slam loads, including drop tests [10-12], scale model tests [13-17] and full scale trials [18, 19], along with several numerical investigations, for example [20, 21]. Davis and Whelan [10] systematically studied CB geometry in drop tests, recommending modifications to bow flare angle and archway clearance of Incat catamarans to reduce the slamming pressures over the impact area. More recent water impact tests by Swidan et al. [11, 12] investigated the relationship between the slamming force, impact velocity, and pressure distribution, highlighting the importance of the $\mathrm{CB}$ design in relation to water build-up within the archways, relative impact angles and velocities. Although these experiments provide valuable insight and benchmark datasets for numerical simulations, they do not consider the actual motions of the vessel in waves. Compared with drop tests, scale model tests can therefore provide greater understanding of slamming loads, pressures and kinematics along the $\mathrm{CB}$, since they satisfy both kinematic and structural similarity conditions.

Hydroelastic Segmented Models (HSMs) simplify the study of the structural loads and responses by focusing on a few specific sections (segments). The segments have tuned elastic connections to properly account for hydroelasticity. Segmented models have been used in many studies on various types of ship for the measurement of vertical bending moments, shear force, slam-induced structural vibratory response (whipping) and identification of slam loads [1, 14, 16, 22-29]. 
Several model experiments in irregular $[17,18,30]$ and regular waves $[1,14,16]$, including systematic tests on CB designs $[5,6,31]$ and ride control performance $[32,33]$ have been conducted over the past decade to identify slamming loads and motions of WPCs in various operational conditions. However, very few have measured pressure, especially in combination with slam loads. Davis et al. [34] tested models in irregular waves, presented longitudinal distributions of slamming pressure as a function of wave encounter frequency, and fitted a polynomial to the slam load as a function relative velocity at slam. Their results indicate that the high peak pressures occur in a large area within the archways and for a broad range of wave encounter frequency. This suggests that the current $\mathrm{CB}$ and archway configurations could be modified to mitigate slamming loads and pressures.

The focus of the present paper is to establish the relationship between slamming force and slamming pressure for various $\mathrm{CB}$ configurations while providing greater insights into peak pressure distribution over the $\mathrm{CB}$ in both longitudinal and transverse directions as a function of wave encounter frequency.

\section{Model set-up and test facilities}

\subsection{Segmented catamaran model and instrumentation}

To identify the slam loads and pressures acting on the CB of the $112 \mathrm{~m}$ Incat catamaran, a $2.5 \mathrm{~m}$ segmented model was instrumented as shown in Figure 2. Table 1 lists the particulars of the model and full-scale vessels. As shown in Figure 2, the four segments of the model are CB, forward, middle and aft. Four elastic links connect the forward, middle and aft segments while the CB was mounted on two transverse aluminium beams attached to the demihulls of the forward segment. Note that the CB segment includes both the forward deck structure and the CB itself, but excludes the forward demihulls and the transverse beams that connect them. A photograph of the catamaran attached to the test carriage at the Australian Maritime College (AMC) towing tank is given in Figure 3. The development of the hydroelastic model is described with full details by Shahraki [35] and Lavroff [36].

The CB was instrumented with 18 pressure transducers, two load cells and two accelerometers, shown in Figure 2. The load cells were placed between the $\mathrm{CB}$ and each transverse beam, providing reactions at two positions on the centre line; inertia load correction using accelerations gave the external (wave) force and moment on the CB.

Table 2 gives details of the instrumentation. A set of Endevco 8510C pressure sensors measured slamming pressures. These had a face diameter of $4 \mathrm{~mm}$ and a rated maximum pressure of $50 \mathrm{psi}(345 \mathrm{kPa})$. The CB was manufactured with embedded fitting plugs on the starboard side (Figure 4) to fit the pressure transducers. Two ATI Mini 45 six component force/moment transducers were used to mount the CB on the transverse beams. Piezoelectric Brüel \& Kjær charge accelerometers measured the CB vertical accelerations for the inertial loads. The model was towed by the forward of two tow posts attached to the carriage; the aft post, on a slider, kept the model aligned and allowed free heave and pitch. Two linear variable differential transformers (LVDTs) measured 
the model vertical displacement at the towing posts. A static wave probe recorded the wave profiles while two moving probes provided relative phase. More details of the wave and motion measurements are provided by Shabani et al. [31].

Table 1 Specifications of the model and full-scale catamaran vessel

\begin{tabular}{lll} 
Description & Model & Full scale \\
\hline Overall length & $2.5 \mathrm{~m}$ & $112.6 \mathrm{~m}$ \\
Water line length & $2.36 \mathrm{~m}$ & $105.6 \mathrm{~m}$ \\
Displacement & $27.12 \mathrm{~kg}$ & 2500 tonnes \\
Overall beam & $0.68 \mathrm{~m}$ & $30.5 \mathrm{~m}$ \\
Beam of hulls & $0.13 \mathrm{~m}$ & $5.8 \mathrm{~m}$ \\
LCG (from transom) & $0.941 \mathrm{~m}$ & $42.15 \mathrm{~m}$ \\
Pitch radius of gyration & $0.69 \mathrm{~m}$ & $30.91 \mathrm{~m}$
\end{tabular}

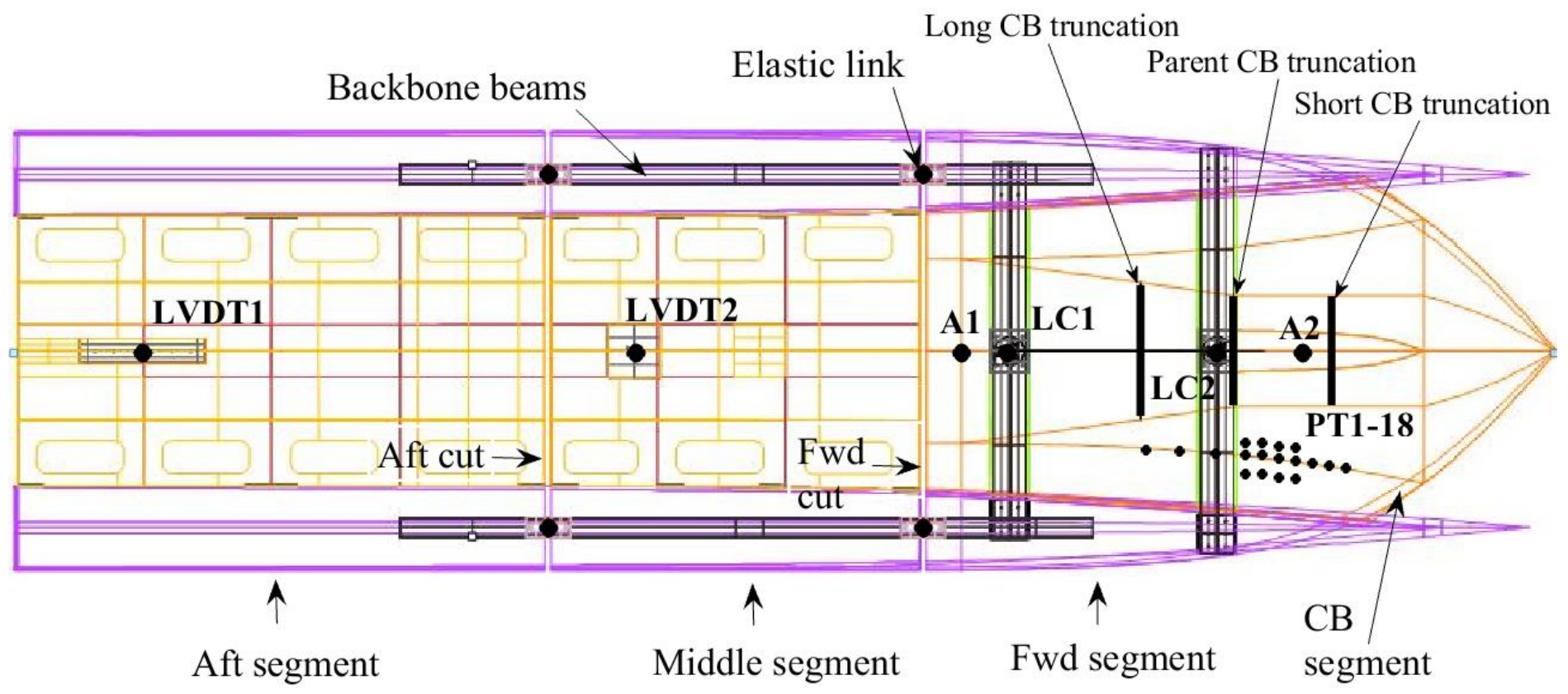

Figure 2 Schematic plan view of the $2.5 \mathrm{~m}$ segmented catamaran model (HSM02) with various centre bow lengths and locations of sensors used for instrumentation. *PT: Pressure Transducer, A: Accelerometer, LC: Load Cell, LVDT: linear variable differential transformers. 


\begin{tabular}{lll} 
Sensors & Quantity & Description \\
\hline Pressure transducers (PT) & 18 & 8510C Endevco piezoresistive pressure transducers \\
Load cells (LC) & 2 & Mini 45 ATI force/moment transducers \\
Accelerometer (A) & 2 & Brüel \& Kjær accelerometers \\
LVDT & 2 & Linear variable differential transformers \\
Wave probes & 3 & Resistive type \\
\hline
\end{tabular}

- Sampling rate for all signals: $10 \mathrm{kHz}$

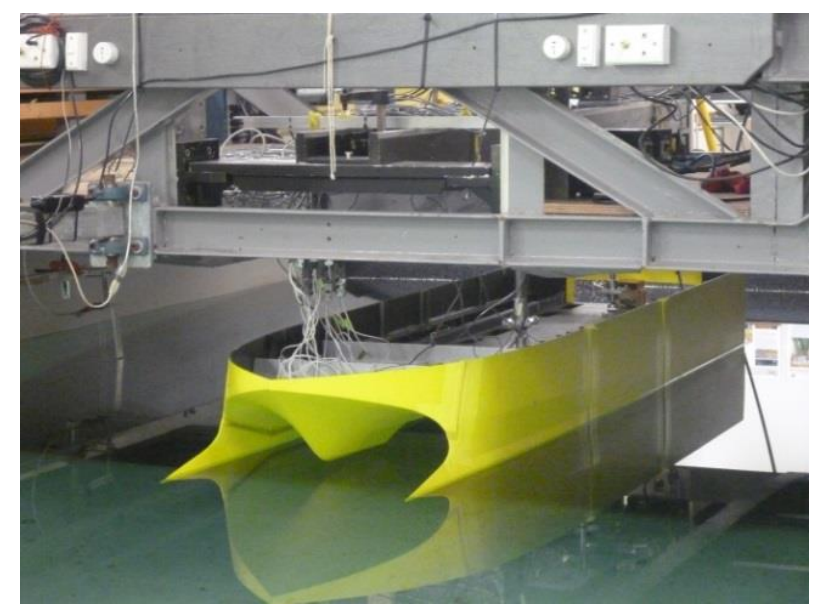

Figure 3 The $2.5 \mathrm{~m}$ catamaran model (HSM02) of the 112-m INCAT wave piercing catamaran

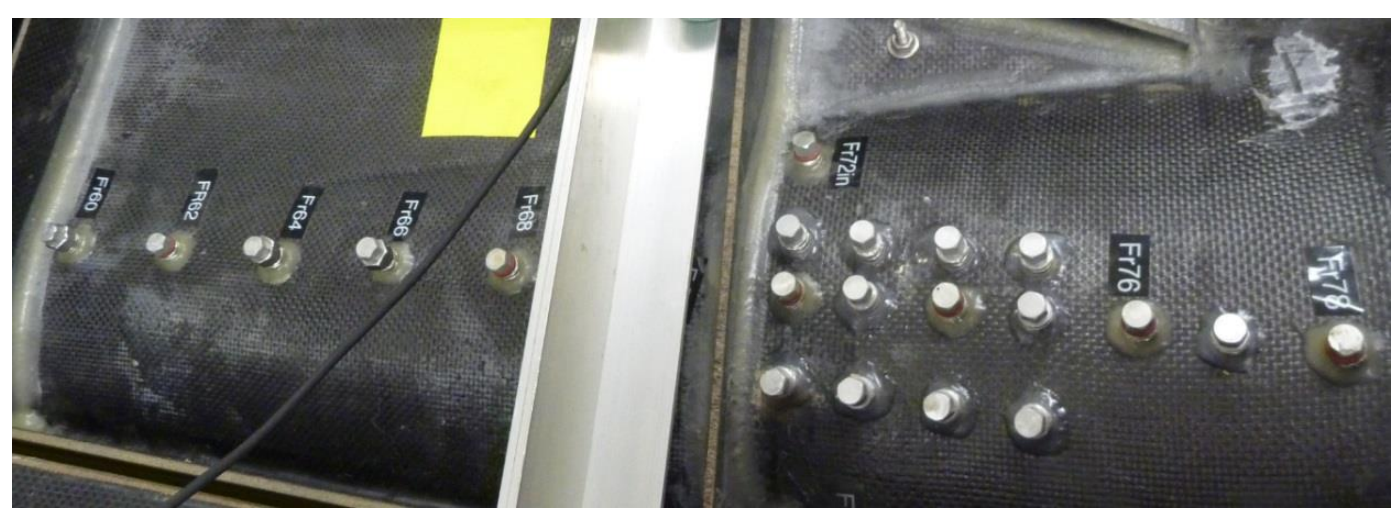

Figure 4 Embedded fitting plugs manufactured on the starboard side of the CB segment

\subsection{Centre bows}

A key parameter in CB design is its length, defined as the longitudinal distance between the truncated section of the $\mathrm{CB}$ and the foremost bow position. Three CBs, with different lengths but similar cross sections and tunnel clearance, are considered in this study, designated as the Parent CB, Long CB and Short CB (see Figure 5 and Table 3). The masses of the Parent and Short CBs were matched to that of the Long CB by adding weight on the 
centreline. It is estimated that the pitch radii of gyration of the catamaran model with various CB length varied by approximately $0.4 \%$ from that of the parent CB $(0.69 \mathrm{~m})$. More details on the construction of the CBs are given by Shahraki [35].

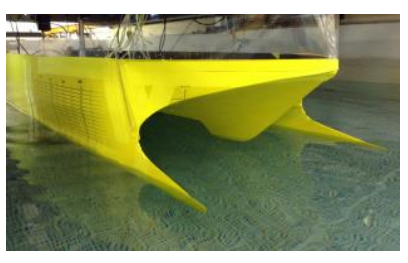

(a)

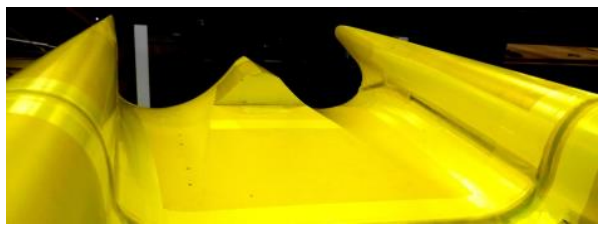

(b)

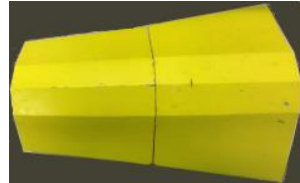

(c)

Figure 5 (a) The catamaran model with the Short CB in water, (b) The catamaran model (upside down) with the Parent CB (c) Two CB extenders which were used to make the Parent CB (left extender) and the Long CB (both extenders) from that shown in (a) for the Short CB. The Parent CB extender is also shown in (b)

Table 3 Main characteristics of various CB configurations after construction

\begin{tabular}{llll} 
& $\begin{array}{l}\text { Tunnel } \\
\text { clearance } \\
(\mathrm{mm})\end{array}$ & $\begin{array}{l}\text { CB* length } \\
(\mathrm{mm})\end{array}$ & $\begin{array}{l}\text { CB length to } \\
\text { model length } \\
\text { ratio }\end{array}$ \\
\hline Long CB & 67 & 758 & 0.303 \\
Parent CB & 67 & 608 & 0.243 \\
Short CB & 67 & 458 & 0.183 \\
* CB: Centre bow & & &
\end{tabular}

\subsection{Location of pressure transducers}

The longitudinal, transverse and vertical positions of the pressure transducers are shown in Figures 6 and 7. The pressure transducers were placed from frame 66 to 78, with numbering based on the full-scale catamaran, counting from the transom with $1.2 \mathrm{~m}$ spacing. This range is between $70 \%$ and $84 \%$ of the overall length from the transom. In the transverse direction, the transducers were located between $40 \%$ and $60 \%$ of the half-beam, and in the vertical direction, they were approximately two to three times the design waterline draft (DWL). There were only 4 inboard and 4 outboard pressure transducers in comparison to 10 at the arch top. The arch top pressure points have zero deadrise angles, while the inboard and outboard points have approximately $+10^{\circ}$ deadrise angle. Note that all three CBs had identical transducer locations, since the CB model segments had the same forward deck, arch structure, and overall length, even though the CBs themselves varied in length. 


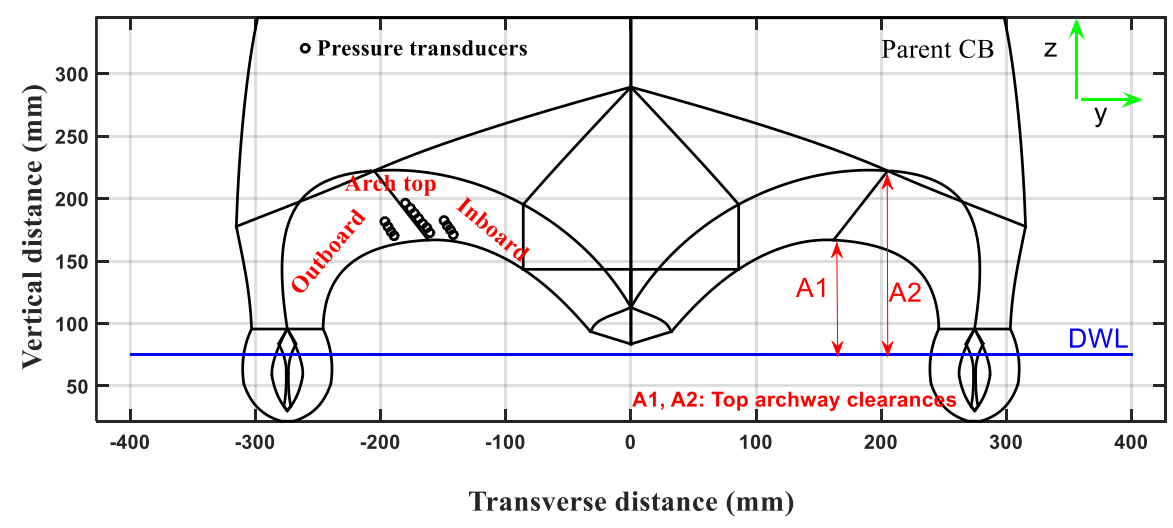

Figure 6 Locations of the outboard, arch top and inboard pressure transducers for the Parent CB

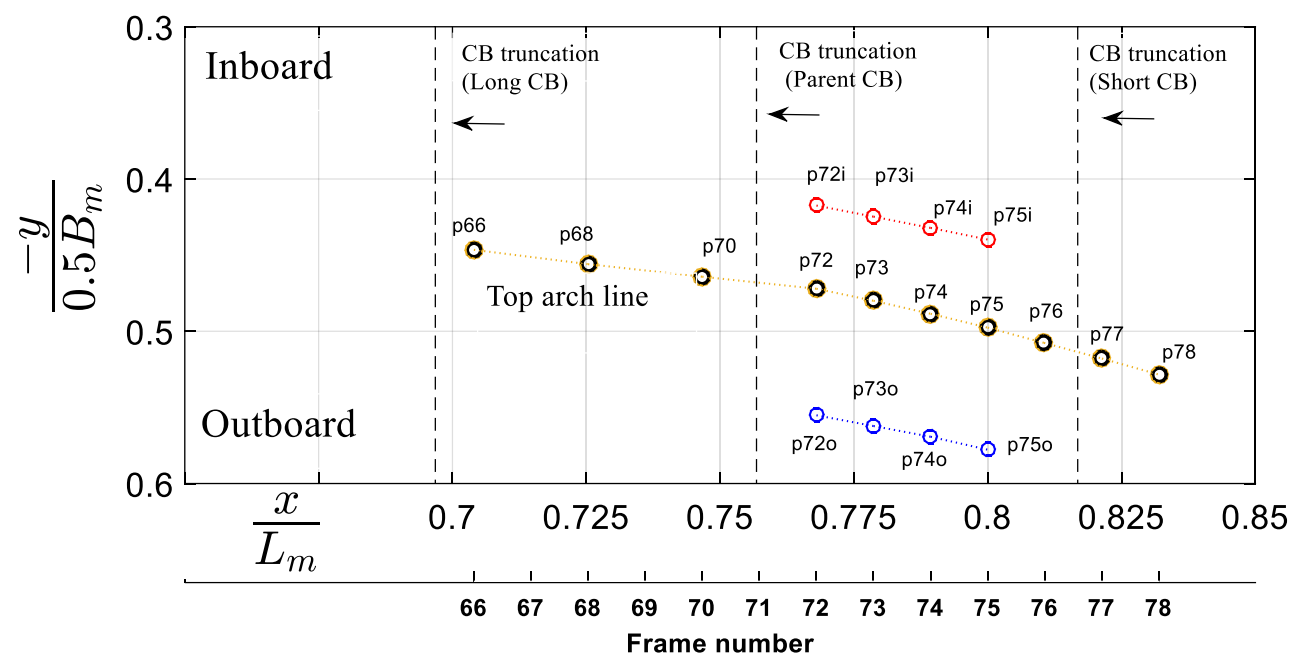

Figure 7 Longitudinal $(x)$ and transverse $(y)$ locations of the pressure transducers for different CB configurations normalised by the length $\left(L_{m}\right)$ and half beam $\left(0.5 B_{m}\right)$ of the catamaran model. $\left(L_{m}=2500 \mathrm{~mm}, B_{m}=680 \mathrm{~mm}\right)$

\subsection{Model test programme}

The catamaran model with each CB was tested in regular waves at $2.89 \mathrm{~m} / \mathrm{s}$, equivalent to $38 \mathrm{knots}$ full-scale, and at two wave heights $60 \mathrm{~mm}$ and $90 \mathrm{~mm}$ equivalent to $2.7 \mathrm{~m}, 4.0 \mathrm{~m}$ at full-scale respectively as listed in Table 4 . Multiple wave frequencies were considered for each test conditions, ranging from 0.35 to $1 \mathrm{~Hz}$, corresponding to 0.05 to $0.15 \mathrm{~Hz}$ at full-scale. It should be noted that test condition 2 (i.e. 38 knots, $4.0 \mathrm{~m}$ ) is more extreme than the normal operating condition for passenger/vehicle catamaran ferries. This is because that the maximum allowable speed for the vessel is only 20 knots at $4 \mathrm{~m}$ significant wave height. However, this condition was of interest to identify very extreme slam loads that may occur. 
A LabView program recorded signals digitised by an M series National Instrument data acquisition card. Very rapid transient pressure spikes necessitated a high sampling rate; DNV recommends $20 \mathrm{kHz}$ [37], but in this present work $10 \mathrm{kHz}$ was found to be adequate, in contrast to the $5 \mathrm{kHz}$ of previous model tests [35, 38, 39]. The AMC towing tank is $100 \mathrm{~m}$ long, $3.55 \mathrm{~m}$ wide, and the water depth was set to $1.4 \mathrm{~m}$.

\section{Table 4 Model test conditions}

\begin{tabular}{llllll} 
& \multirow{2}{*}{ Centre bow } & \multicolumn{2}{c}{ Model scale } & \multicolumn{2}{c}{ Full-scale } \\
& & Velocity & Wave height** & $\begin{array}{l}\text { Velocity } \\
\text { (knots) }\end{array}$ & Wave height \\
& & & & $V_{s}($ knots $)$ & $H(\mathrm{~m})$ \\
Condition 1 & long, parent and short CBs & 2.89 & 60 & 38 & 2.7 \\
Condition 2 & long, parent and short CBs & 2.89 & 90 & 38 & 4.0 \\
\hline
\end{tabular}

* Multiple wave frequencies were considered for each test condition, ranging from 0.37 to $.93 \mathrm{~Hz}$, corresponding to 0.05 to 0.14 $\mathrm{Hz}$. The average increment of wave frequency in model scale was approximately $0.025 \mathrm{~Hz}$.

\section{Experimental results}

\subsection{Slamming occurrences}

Figure 8 shows the model with the Long CB before and after a slamming event involving large heave and pitch amplitudes in $90 \mathrm{~mm}$ wave height and at dimensionless encounter frequency of $\omega_{\mathrm{e}}^{*}=4.82$ [31]. Equation 1 presents the dimensionless wave encounter frequency $\left(\omega_{e}^{*}\right)$ as a function of the encounter circular wave frequency $\left(\omega_{e}\right)$, the model length $\left(L_{m}\right)$ and acceleration due to gravity $(g)$,

$$
\omega_{e}^{*}=\omega_{e} \sqrt{\frac{L_{m}}{g}} .
$$

In this event, the $\mathrm{CB}$ penetrated into waves and the immersion depth increased until the water apparently filled the archways. Figures 8(a-b) show the progress of lateral jet flow when the CB pitches into the waves. The arch closure occurred over a few milliseconds, exerting a rapid force impulse on the CB. Figure 8(c) shows the deformation of the water during the $\mathrm{CB}$ exit (i.e. after experiencing the slam), in which the lateral jet flow developed on the CB surface forward of the jaw line and passed outwards above the forward bows of the demihulls. Frame by frame analysis of video recordings showed that a fraction of the entrapped water seems to discharge longitudinally in the forward direction. Therefore, the displacement of water by the bow as it becomes immersed can be considered in two stages: (1) lateral water jets due to bow entry (2) longitudinal water discharge from the archways due to slamming. The latter is related to the volume of the water that is entrapped within the archways and discharged after the slamming event. 


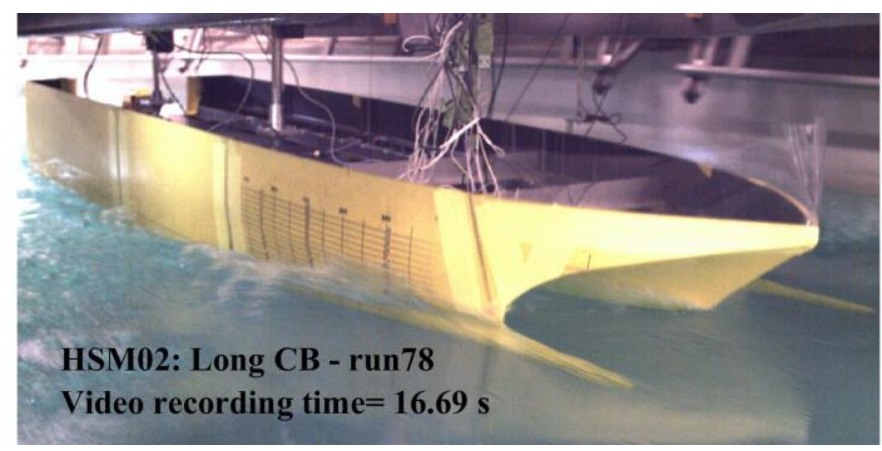

(a)

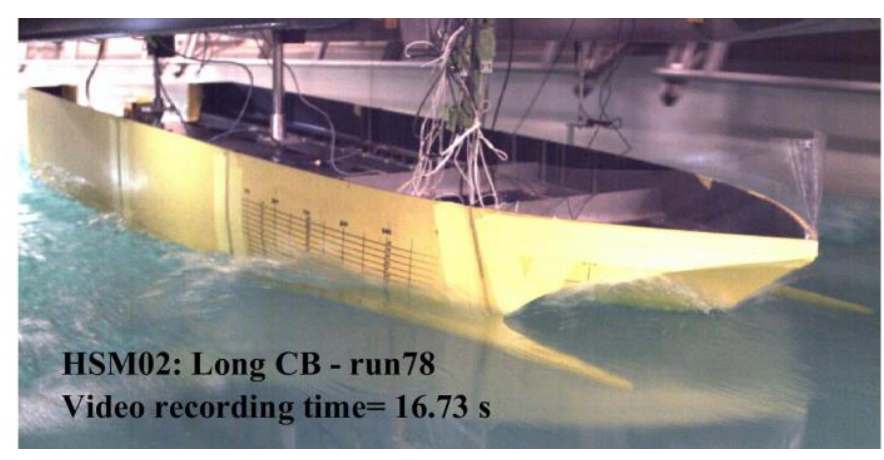

(b)

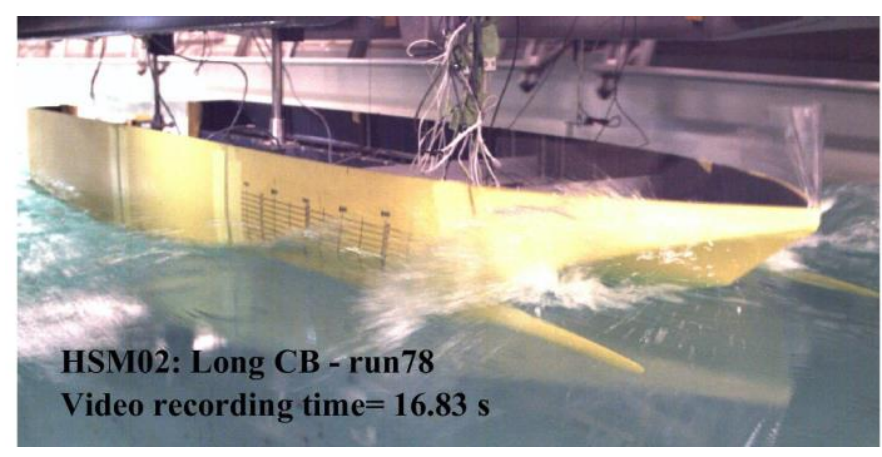

(c)

Figure 8 (a) The CB water entry, (b) formation of lateral jet flow across the demi mull bows and (c) post slam water discharge in a forward direction from archways for the Long CB in $h_{w}=90$ and $V_{m}=2.89 \mathrm{~m} / \mathrm{s}$ at $\omega_{e}^{*}=4.82$.

\subsection{Centre bow slamming loads}

Loads acting on the CB were those measured by the load cells, corrected for CB inertia using the measured accelerations (details in $[34,35]$ ). Figure 9 shows sample time records for the Parent $C B$ at three selected dimensionless wave encounter frequencies in 60 and $90 \mathrm{~mm}$ waves. Although the model tests were conducted in regular waves, the $\mathrm{CB}$ vertical forces showed significant variations in peak magnitudes. In Figure 9, dashed lines connect the peaks. As can be seen, the pattern obtained at $\omega_{e}^{*}=6.3$ by connecting consecutive peaks is dissimilar to that obtained for $\omega_{e}^{*}=4$ and $\omega_{e}^{*}=4.5$ in two aspects. First, the peaks at $\omega_{e}^{*}=6.3$ tend to follow a long undulating curve rather than a short triangular pattern of alternate peaks, which is the case for the other two frequencies. Second, it seems that the variability of peaks at $\omega_{e}^{*}=6.3$ tends not to reduce as time increases. The 
slam peak variability seems to be related to corresponding model motion variability according to raw pitch and heave data.

Another important consideration in analysing the vertical CB loads is that the peak CB loads are not identical to peak slam loads. The CB load is in fact a superposition of the bow entry and slam load as shown in Figure 10. Therefore, the vertical slam force $\left(F_{z}^{\text {slam }}\right)$ is

$$
F_{z}^{\text {slam }}=F_{z}^{\max }-F_{z}^{\text {be }}
$$

where, $F_{Z}^{\max }$ is the peak vertical force acting on the CB segment at the slam instant, and $F_{Z}^{\text {be }}$ is the maximum bow entry force. Here, the time at which the CB vertical force is at its maximum is defined as the slam instant [40] .

Filtering was used to estimate $F_{z}^{\text {be }}$, which is defined as the maximum of an underlying load (shown by a dashed line in Figure 10) obtained by applying a 5th order low-pass Butterworth filter with $5 \mathrm{~Hz}$ cut-off frequency on the CB vertical force signal [38]. Alternatively, a cut-off frequency of twice the wave encounter frequency was trialled but made no significant change to results.

Figure 10 also shows that slamming initiated high frequency vibrations in the range $65-75 \mathrm{~Hz}$ in the CB segment, and whipping in the range $12-14 \mathrm{~Hz}$. The former represents local vibration of the CB relative to the forward segment, while the latter represents global bending vibrations. These vibrations do not influence the succeeding slam force as they decay quickly. The time intervals, prior to $6.95 \mathrm{~s}$ and after $7.35 \mathrm{~s}$, in which the centre bow immersion is zero (i.e. where the CB can be considered 'dry') are shown in Figure 10. After the slamming and during the exit phase, the vertical force on the bow can be negative as some volume of the surrounding fluid should be displaced when the bow is moving relatively upward and out of the encountered wave. The kinematic conditions leading to slamming occurrences, which mainly depends on the relative position of the centre bow with respect to the wave surface or centre bow immersion, were previously investigated by Shabani et al. [41].

Slam loads increased significantly with both the CB length and wave height, as shown in Figure 11 (a \&b). The medians of slam loads are approximately $105 \mathrm{~N}, 65 \mathrm{~N}$ and $50 \mathrm{~N}$ in $60 \mathrm{~mm}$ waves and $225 \mathrm{~N}, 150 \mathrm{~N}$ and $100 \mathrm{~N}$ in $90 \mathrm{~mm}$ waves for the Long, Parent and Short CBs respectively, while the most severe slam load was roughly 330 $\mathrm{N}$, about $25 \%$ higher than the weight of the $2.5 \mathrm{~m}$ catamaran model. The slam loads divided by the length of centre bows, provided in Table 3, are given in Figure 11 (c\&d). As it can be seen, the increase of the CB length resulted in disproportional increases of slamming loads as evident from the range of slam loads per CB length. The variations of slamming loads for various centre bows as a function of wave encounter frequency are given in Shabani et al. [40]. 


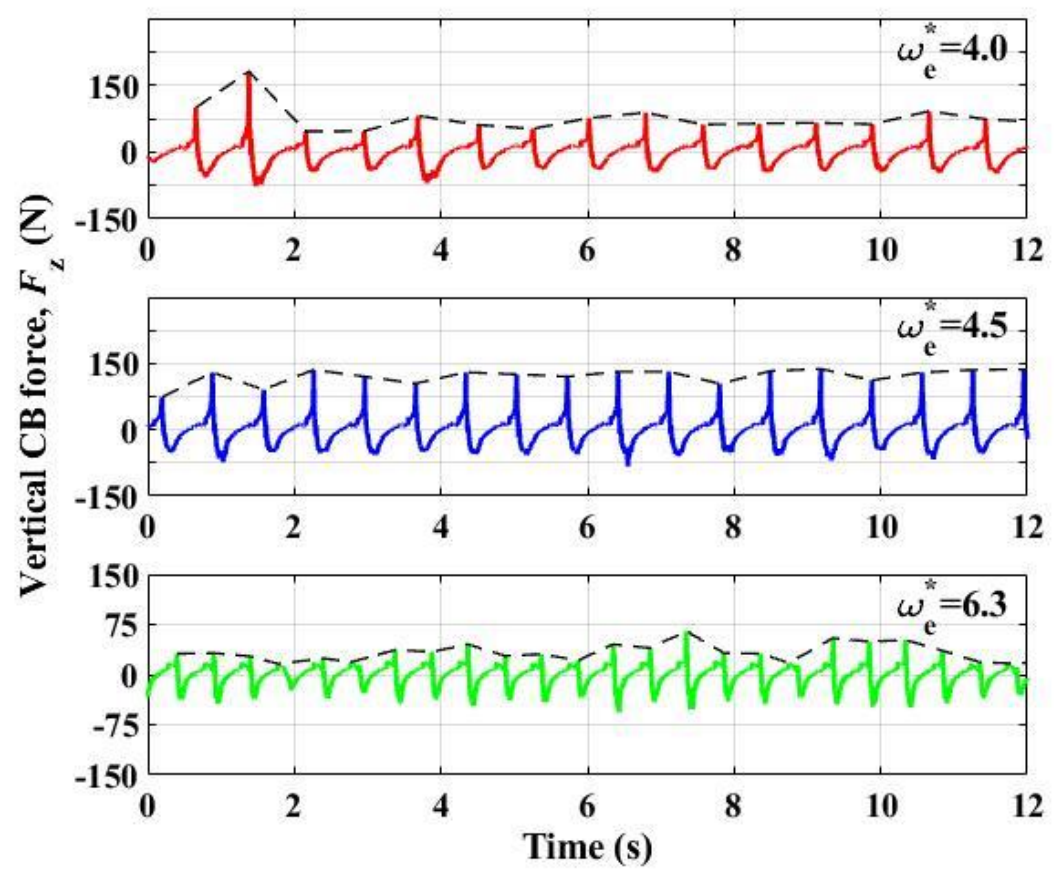

(a)

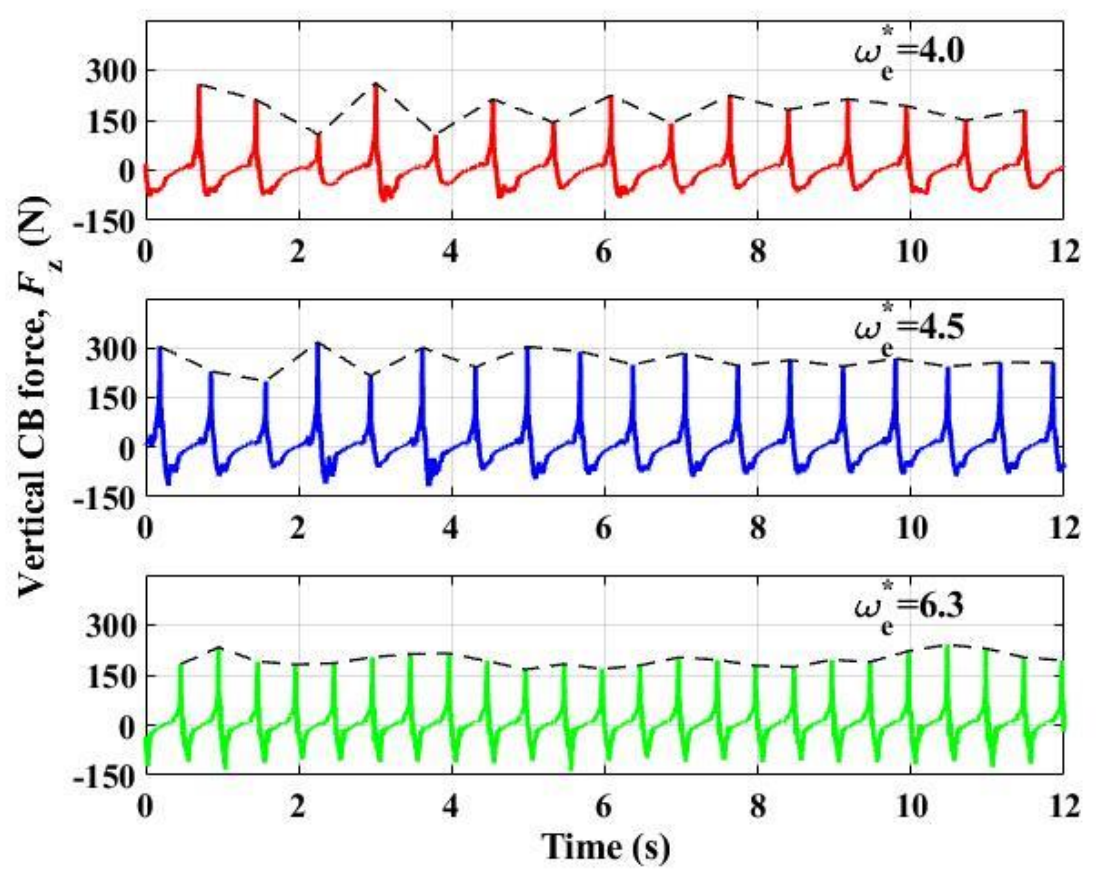

(b)

Figure 9 Peak load patterns at $\omega_{e}^{*}=4,4.5$ and 6.3 for the Parent CB at a speed of $2.89 \mathrm{~m} / \mathrm{s}$ at (a) $60 \mathrm{~mm}$ wave height (b) $90 \mathrm{~mm}$ wave height 


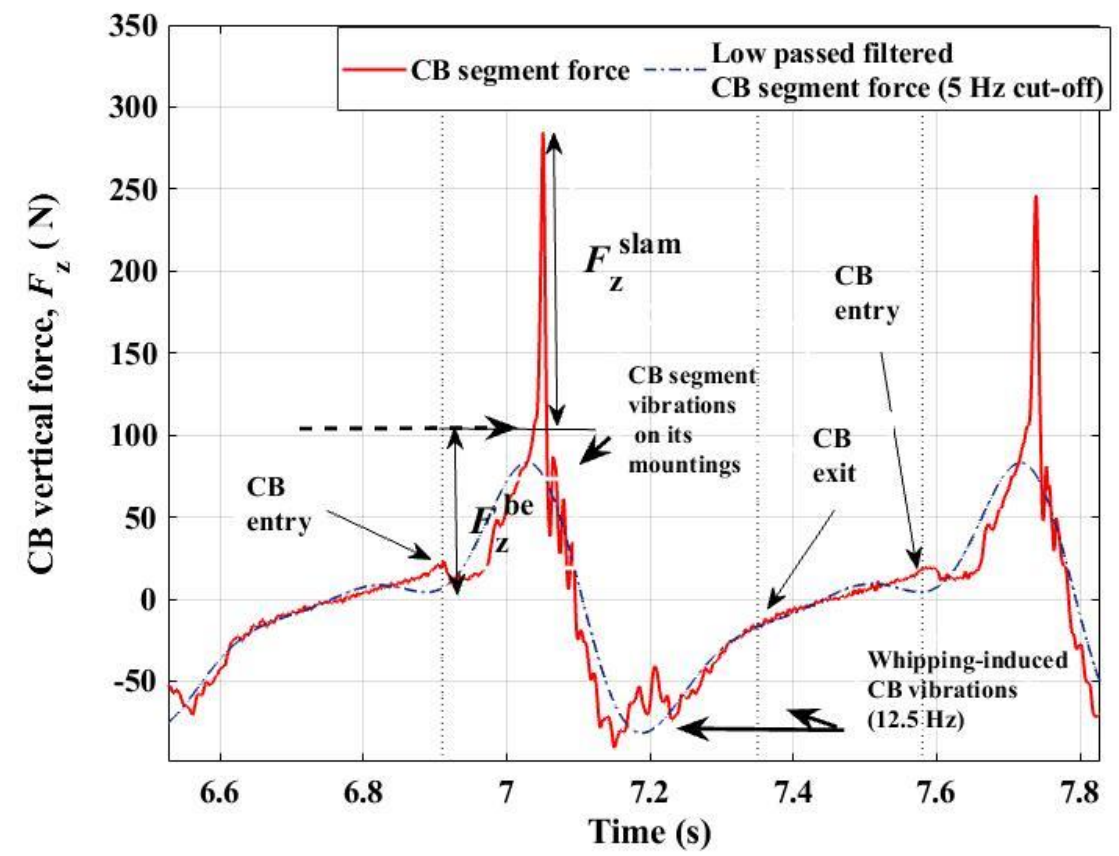

Figure 10 The vertical bow entry and slam forces acting on the Parent CB for a slam event at $\omega_{\mathrm{e}}^{*}=4.5$ at a speed of $2.89 \mathrm{~m} / \mathrm{s}$ at $90 \mathrm{~mm}$ wave height 


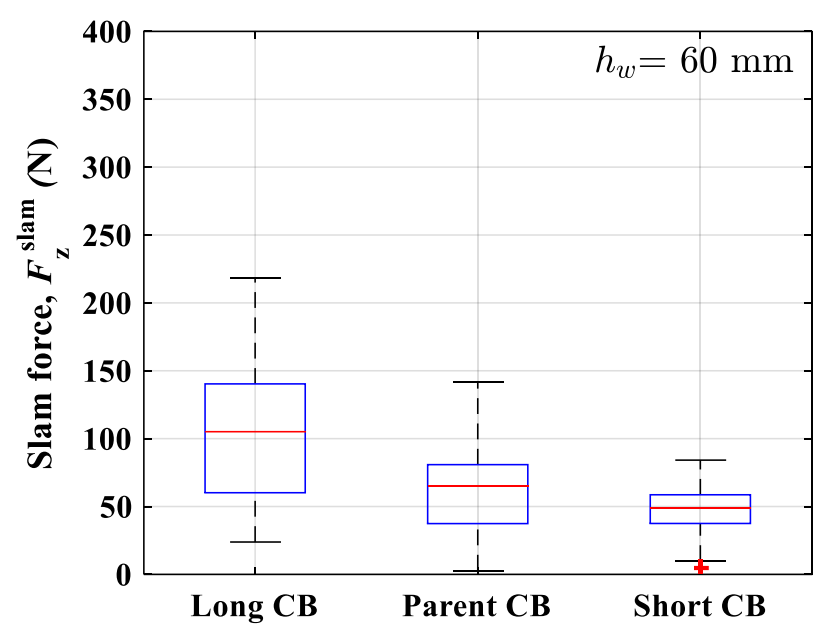

(a)

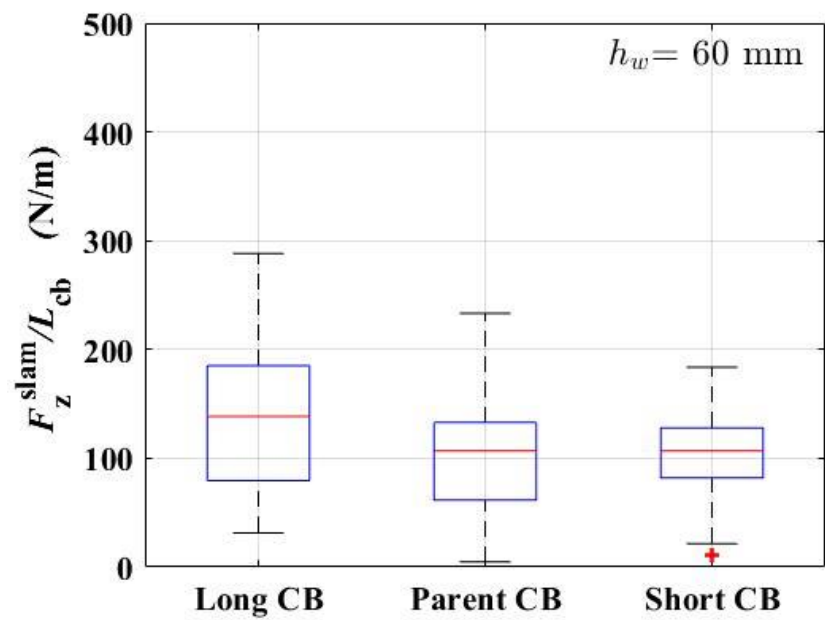

(c)

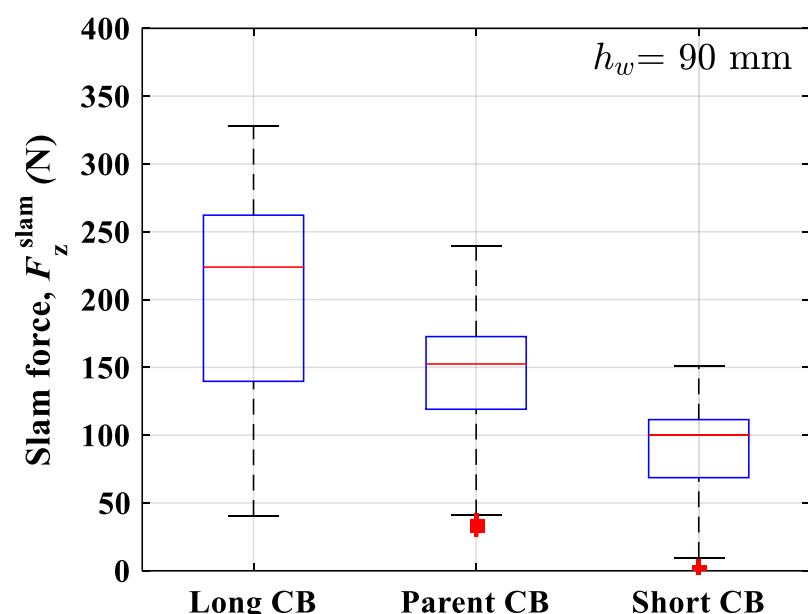

(b)

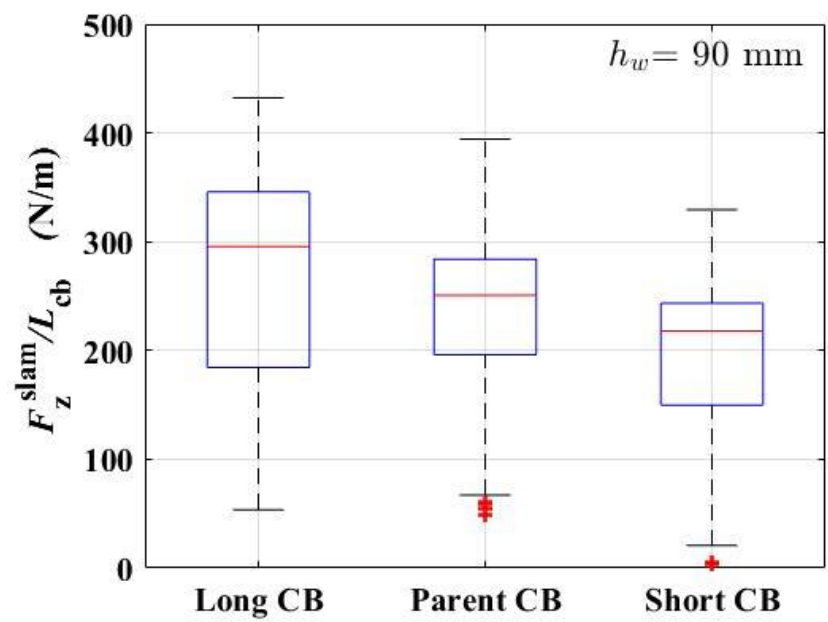

(d)

Figure 11 The distribution of vertical slamming forces (top) and vertical slamming forces per centre bow (bottom) length identified for each CB in (a \& c) $h_{w}=60 \mathrm{~mm}(\mathrm{~b} \& d) h_{w}=90 \mathrm{~mm}$

\subsection{Slamming pressures}

Figure 12 shows examples of the slam pressure signals in $90 \mathrm{~mm}$ waves for the Parent $\mathrm{CB}$. As can be seen, the signals rise suddenly from zero to the peak at the slam instant. The sharp rise of the pressure pulses from the prolonged zero values when the local surface is dry makes the pressure pulse suitable for slam identification. This provides a direct indication of wet-deck slam occurrences, as opposed to load signals that have impulsive responses superimposed on a slower varying pattern induced by the bow entry [38]. However, the peak times for different transducers differ both longitudinally, as shown in Figure 12(a), and transversely, as shown in Figure 12(b). Hence, to determine a unique slam instant, the peak slam load was used in preference to the peak slam pressure as a reference. 
To illustrate the adequacy of sampling rate, a pressure pulse sampled at $10 \mathrm{kHz}$ is shown in Figure 13 . The arch filling process is considered as a transient stage after the bow entry and prior to slamming. During arch filling, the rate of change of the pressure signal is significantly lower than the rate of change during the wet-deck slamming stage. The region identified in Figure 13 as pulse width shows the duration of slamming pressure. In this example, the 'pulse width' of slam pressure is about $3 \mathrm{~ms}$ whereas the 'rise time' (region 1 on the figure) is approximately $25 \mathrm{~ms}$. There are about 30 data points that shape the slamming pressure pulse. Although it seems that $10 \mathrm{kHz}$ sampling rate provided adequate data points for the measurement of the slamming pressure pulse, there is a possibility that the peak pressures was missed. However, with 30 points shaping the peak the effect of sampling on the identified maximum pressure is expected to be relatively small.

On the other hand, consideration should be given to the effect of the CB structural vibrations on the measured peak values because these vibrations have very high frequency and can affect the peak pressure measurements. The very high peak pressures may not be practically useful in terms of the ship structural design when hydroelasticity is important [42-45], and a rational evaluation of measured peak pressures is necessary prior to estimation of wave impact loads for structural design purposes [46]. Therefore, missing a peak pressure even by a modest degree seems to be not problematic if they are associated with structural CB vibrations which is likely to be the case here.

It is worth noting that the timing of the corresponding slamming pulse width was approximately 20 ms based on the slamming load shown in Figure 10. Therefore, a time window from $10 \mathrm{~ms}$ prior to $10 \mathrm{~ms}$ after the slam is sufficient to analyse the variations of slamming pressures, discussed next.
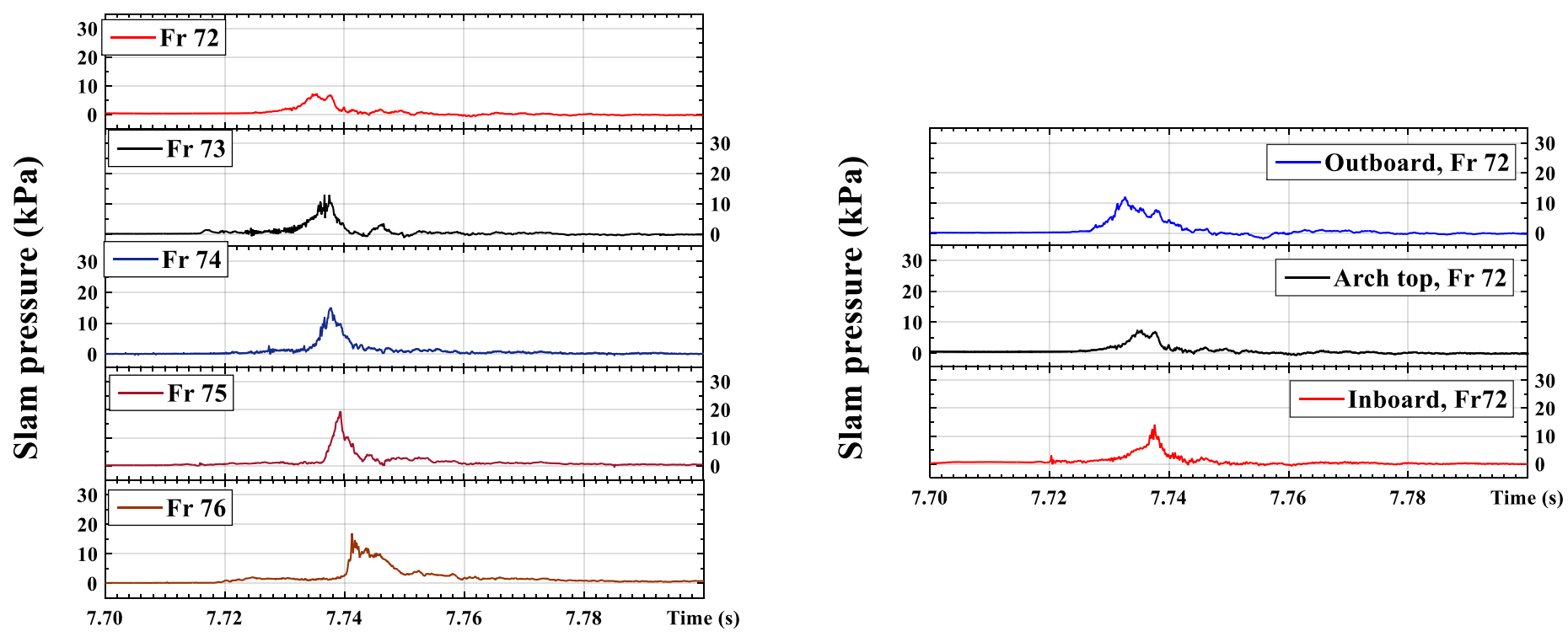

Figure 12 Pressure time records obtained at $\omega_{e}^{*}=4.5$ for a speed of $2.89 \mathrm{~m} / \mathrm{s} \mathrm{in} 90 \mathrm{~mm}$ wave height from transducers located at different frame (Fr) locations 


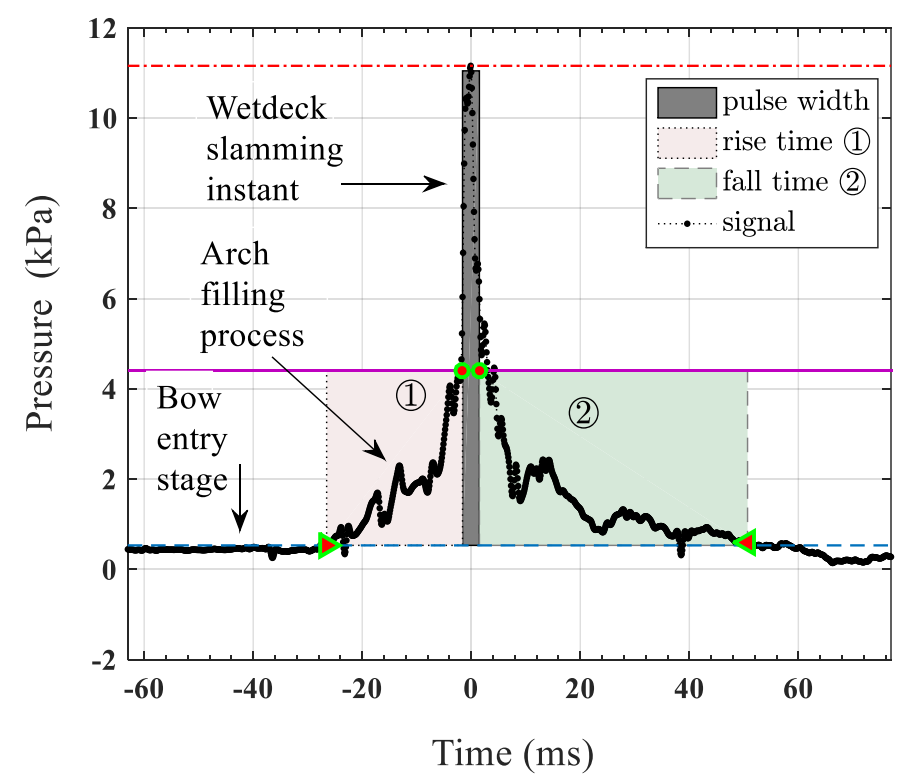

Figure 13 A slam pressure record illustrating the number of data points sampled at $10 \mathrm{kHz}$ for arch filling and wet-deck slamming stages.

\subsection{Distribution of slam pressures as a function of time and wave encounter frequency}

Figure 14 shows measured pressures as a function of time relative to a slam instant at $t_{s}=4.99 \mathrm{~s}$ for the Parent CB at $\omega_{e}^{*}=4.57$ in $90 \mathrm{~mm}$ waves. The measured pressure distributions are shown in successive frames from $10 \mathrm{~ms}$ prior to the slam to $8 \mathrm{~ms}$ after the slam in increments of $2 \mathrm{~ms}$. The inset figure on each plot shows the slam vertical force versus time profile, with a dotted line and marker indicating the time corresponding to the pressure distribution plot in the main chart.

The variations of slamming pressures along the centre bow in outboard, arch top and inboard regions, as defined earlier in Figure 6, are also shown in Figure 14. As can be seen in Figure 14 (b-d) the slam pressure starts to increase progressively from the outboard to inboard region in the range $8 \mathrm{~ms}$ to $4 \mathrm{~ms}$ prior to the slamming instant. The arch top and inboard pressures suddenly rise at the slam instant $(\Delta t=0)$, with the inboard pressure experiencing the overall maximum as shown in Figure 14(f). There is less difference amongst the inboard, arch top and inboard pressures in post slamming times $(\Delta t>0)$ compared to prior to slamming $(\Delta t<0)$. This suggests the lateral jet flow within the archways prior to slamming causes pressure variations, while the more uniform post slamming pressure seems to be linked to the longitudinal rather than lateral flow within the archways. This can be seen in Figure $14(\mathrm{f}-\mathrm{i})$ where the locations of high pressures shift from $78 \%-80 \%$ of the overall length from the transom towards $82 \%-84 \%$ as the $\Delta t$ increases from $\Delta t=0$ to $\Delta t=6 \mathrm{~ms}$.

Further analysis showed significant variation between individual slam events within each single run, but some characteristics of pressure distribution along the archways remained unchanged. This is illustrated in Figure 15 
which shows the pressure distributions at the slamming instant $(\Delta t=0)$ for consecutive slams from $t_{s}=4.99 \mathrm{~s}$ to $t_{s}=11.17 \mathrm{~s}$, showing the CB peak vertical loads in the range 250-300 N. The inboard and top arch pressures at $\Delta t=0$ were higher than the outboard pressures for most of the slam instants shown in Figure 15(a-j). It is also evident that the peak pressures outside the archways (outside $76-82 \%$ of the overall length from transom) were several times smaller than the pressures within the archways.

Moreover, the pressure peaks identified in a single run at each measurement points show a high level of variability, as illustrated in Figure 16 for the Parent CB at a selection of wave encounter frequencies in $90 \mathrm{~mm}$ waves. Each box-and-whisker plot represents the variations of peak pressures obtained by a pressure transducer during a single run. For each frame from 72 to 75, three adjacent box plots represent from left to right the inboard, arch top and outboard transducers. The bottom and top edges of the boxes are the 25th and 75th percentile, and the end of whiskers show approximately 99.3 coverage assuming a normal distribution in peak pressure samples. Although these tests were carried out in regular head seas there is a significant variation of slamming pressure between events. Clearly the slam process when examined at the small physical scale of point pressure measurements is not perfectly regular and shows a somewhat chaotic variation; the data presented here give an indication of this variability. 
(a)

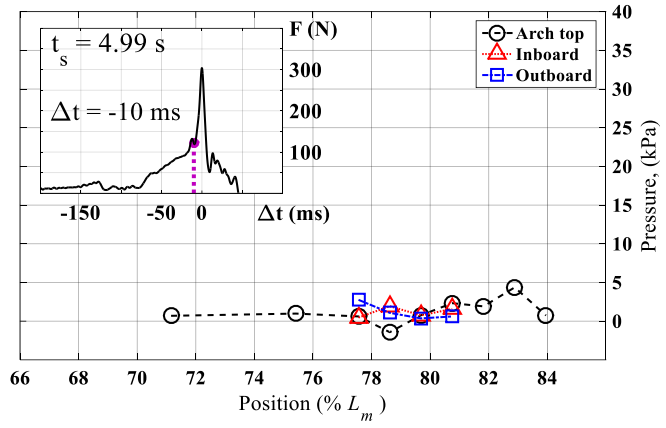

(b)

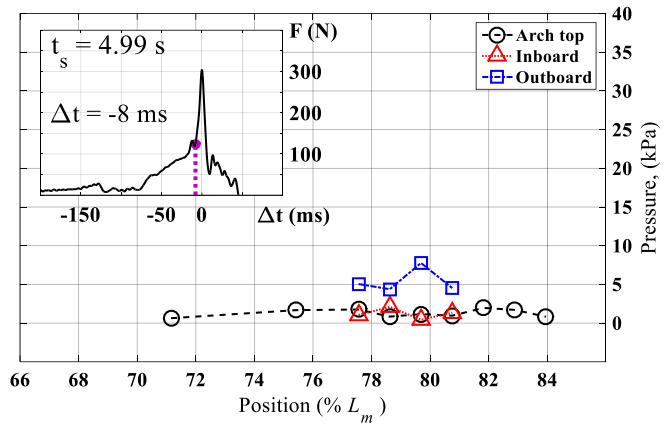

(c)

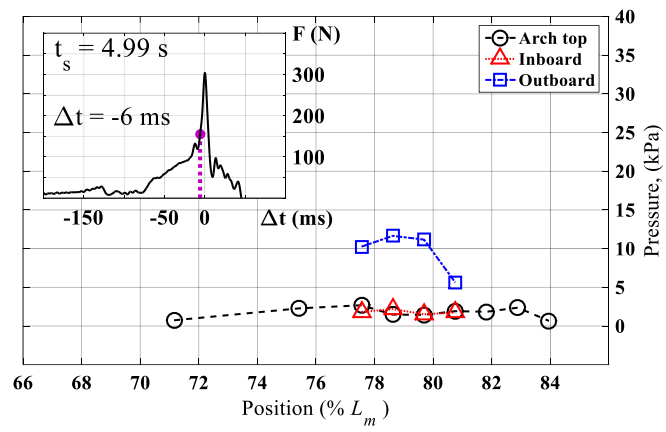

(d)

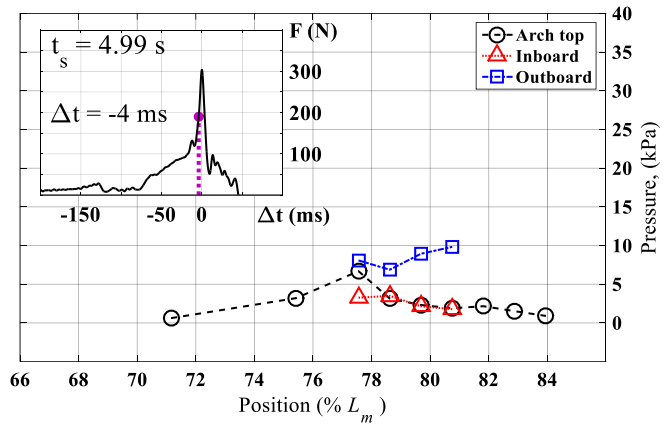

(e)

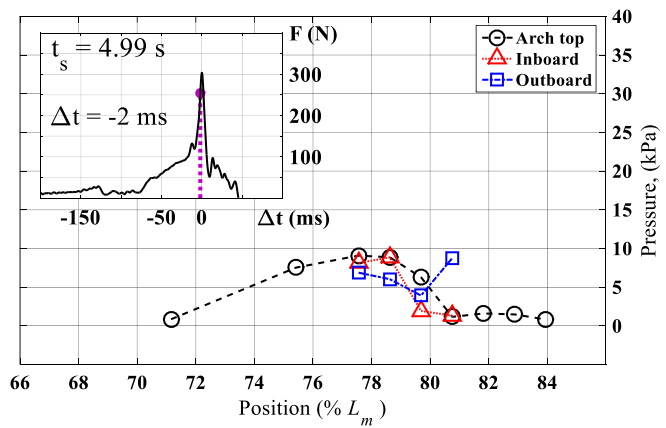

(f)

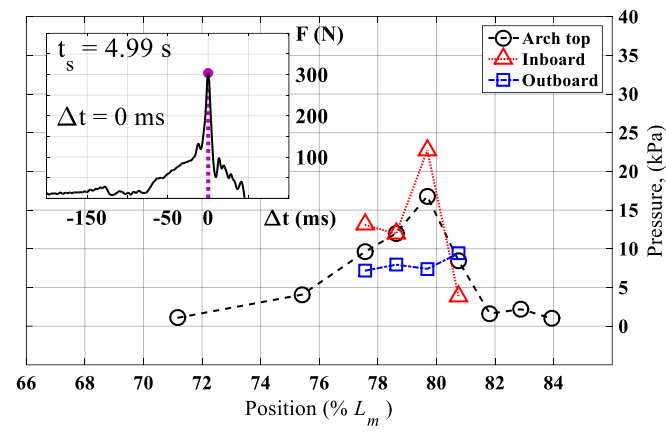

(g)

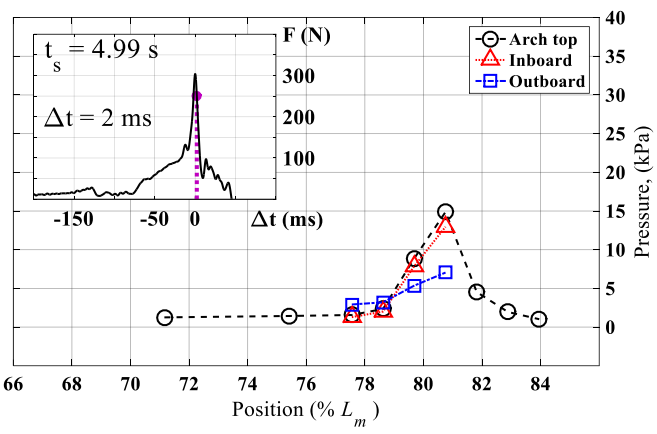

(h)

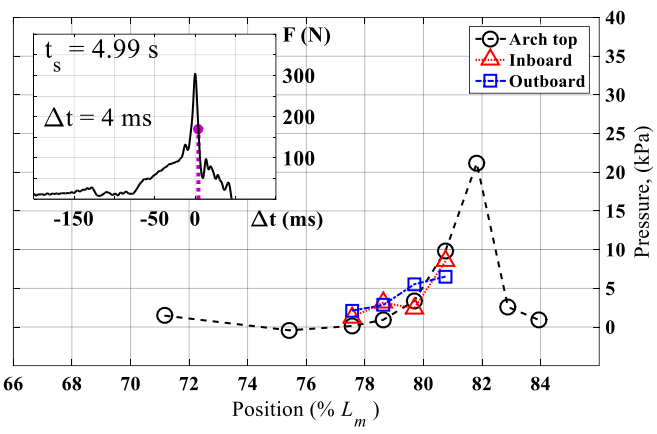

(i)
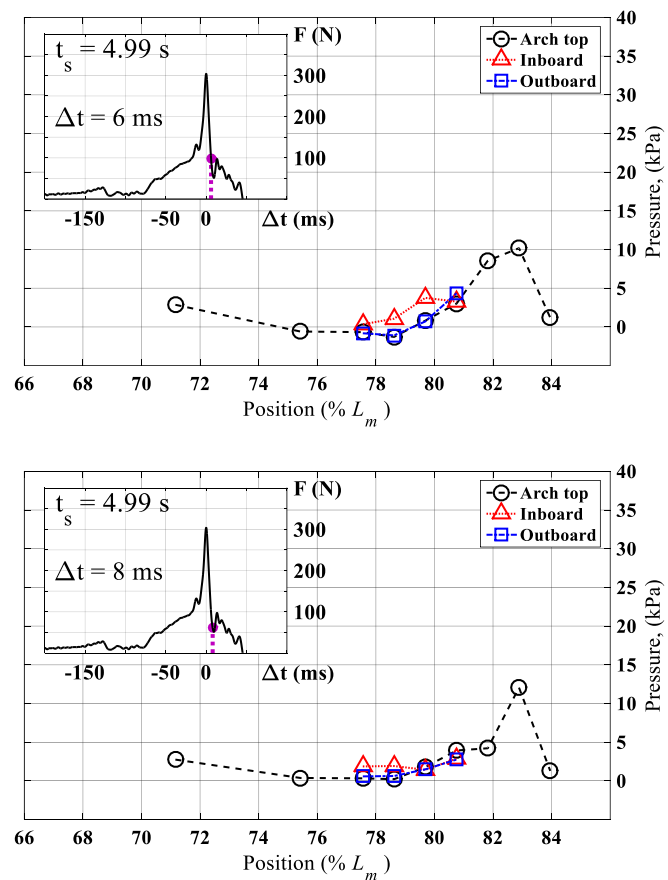

Figure 14 Measured pressures at different longitudinal positions obtained for different times relative to a slam instant $t_{s}=4.99 \mathrm{~s}$ at $\omega_{e}^{*}=4.57$ for the Parent $C B$ in $90 \mathrm{~mm}$ waves at $2.89 \mathrm{~m} / \mathrm{s}$ model speed. (a) $\Delta t=-10 \mathrm{~ms}$, (b) $\Delta t=-8 \mathrm{~ms}$, (c) $\Delta t=-6 \mathrm{~ms}$, (d) $\Delta t=-4 \mathrm{~ms}$, (e) $\Delta t=-2 \mathrm{~ms}$, (f) $\Delta t=0 \mathrm{~ms}$, (g) $\Delta t=2 \mathrm{ms,} \mathrm{(h)} \Delta t=4 \mathrm{~ms}$, (i) $\Delta t=6 \mathrm{~ms}$, (j) $\Delta t=8 \mathrm{~ms}$. 
(a)

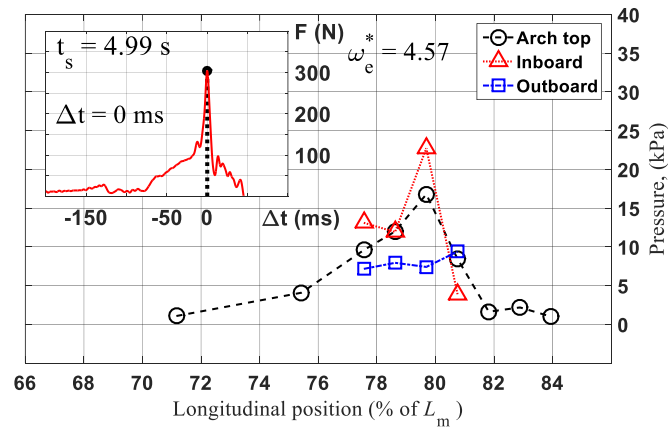

(b)

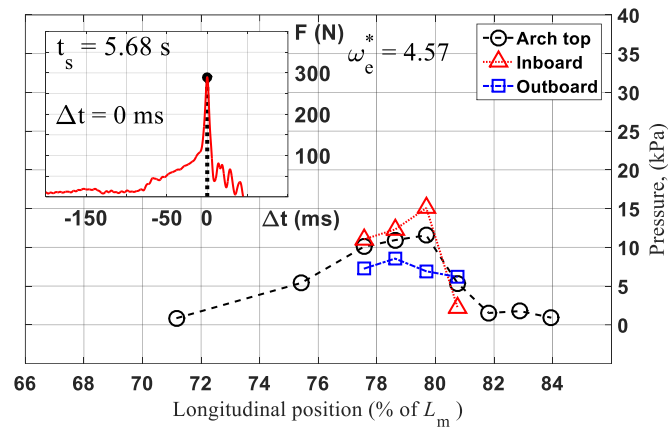

(c)

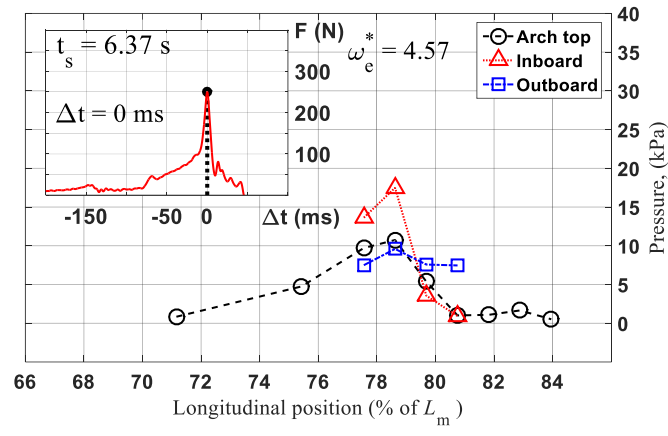

(d)

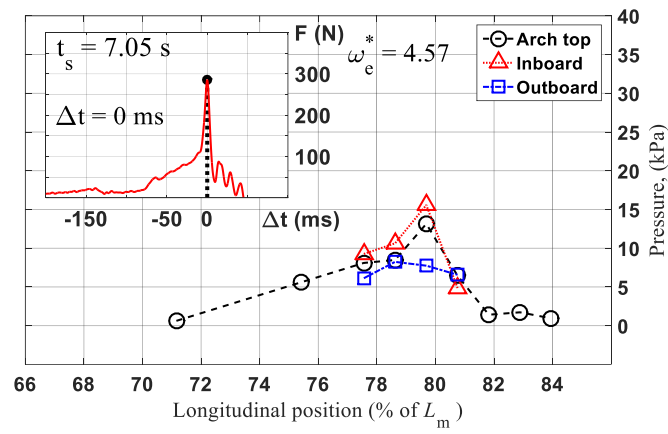

(e)

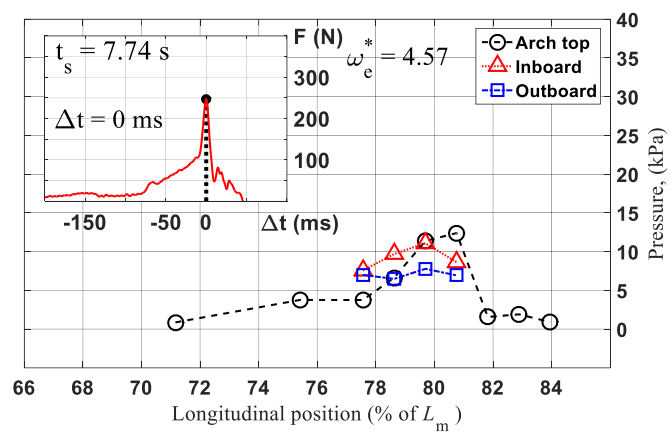

(f)

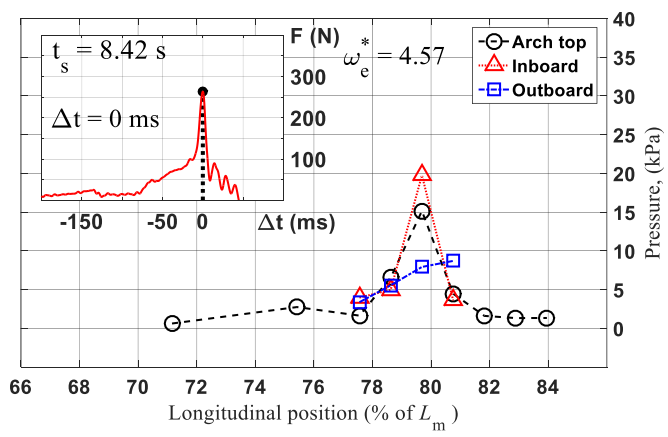

(g)

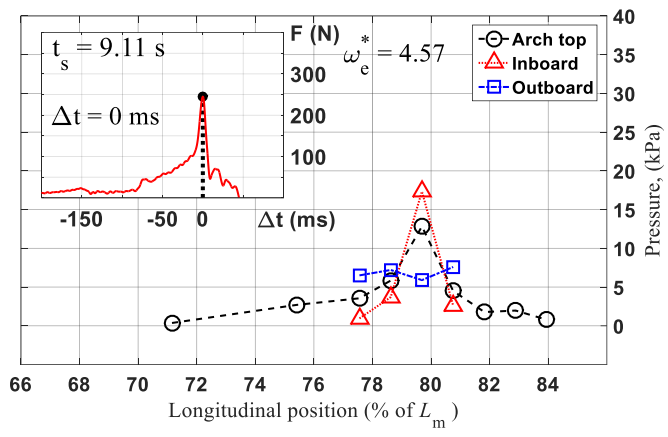

(h)

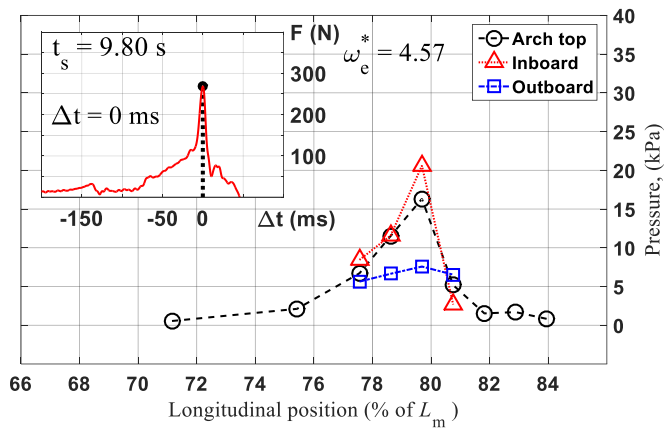

(i)

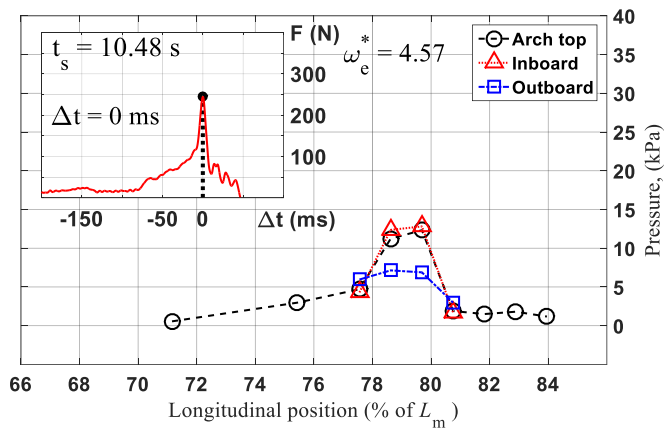

(j)

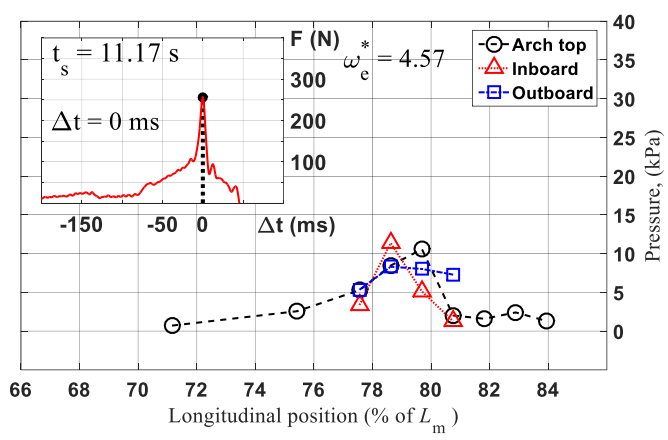

Figure 15 Measured CB loads and pressures at different longitudinal positions for consecutive slam instants in a single run at $\omega_{e}^{*}=4.57$ for the Parent CB in $90 \mathrm{~mm}$ waves at $2.89 \mathrm{~m} / \mathrm{s}$ model speed. (a) $t_{s}=4.99 \mathrm{~s}$, (b) $t_{s}=5.68 \mathrm{~s}$, (c) $t_{s}=6.37 \mathrm{~s}$, (d) $t_{s}=7.05 \mathrm{~s}$, (e) $t_{s}=7.74 \mathrm{~s}$, (f) $t_{s}=8.42 \mathrm{~s}$, (g) $t_{s}=9.11 \mathrm{~s}$, (h) $t_{s}=9.80 \mathrm{~s}$, (i) $t_{s}=10.48 \mathrm{~s}$, (j) $t_{s}=11.17 \mathrm{~s}$. 
(a)

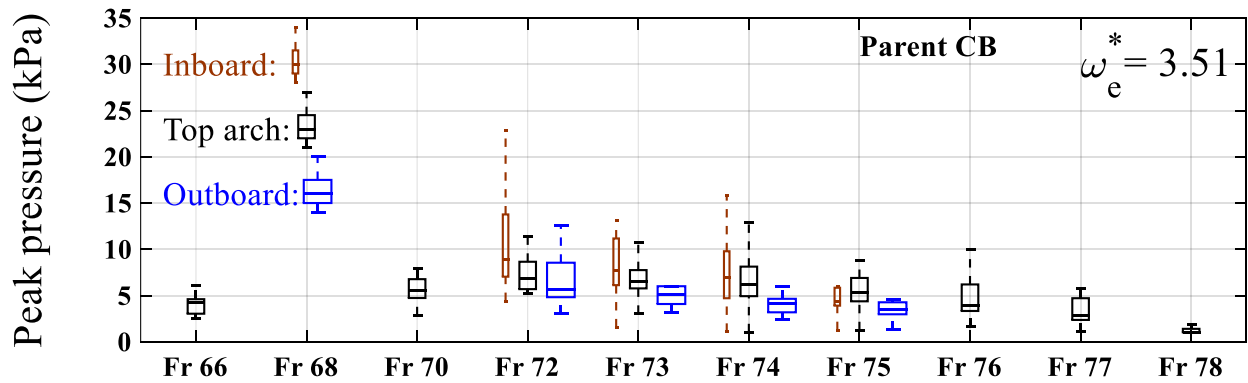

(b)

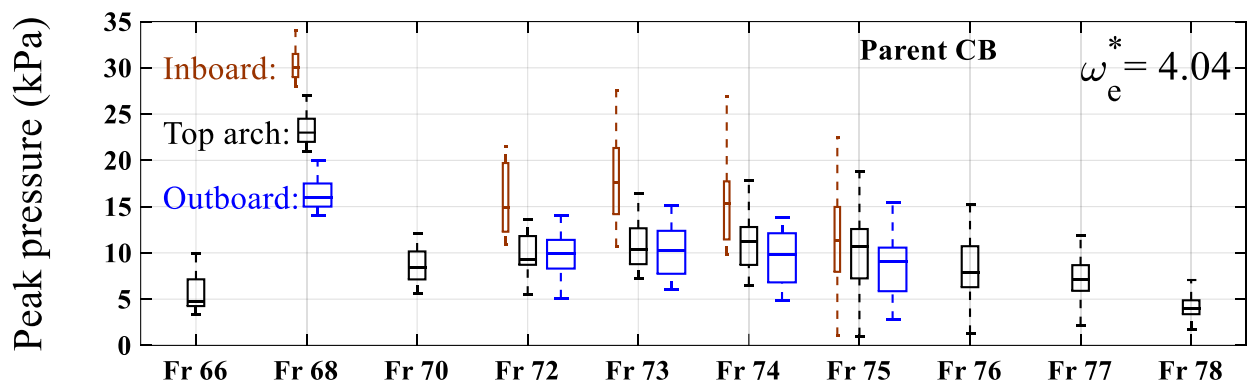

(c)

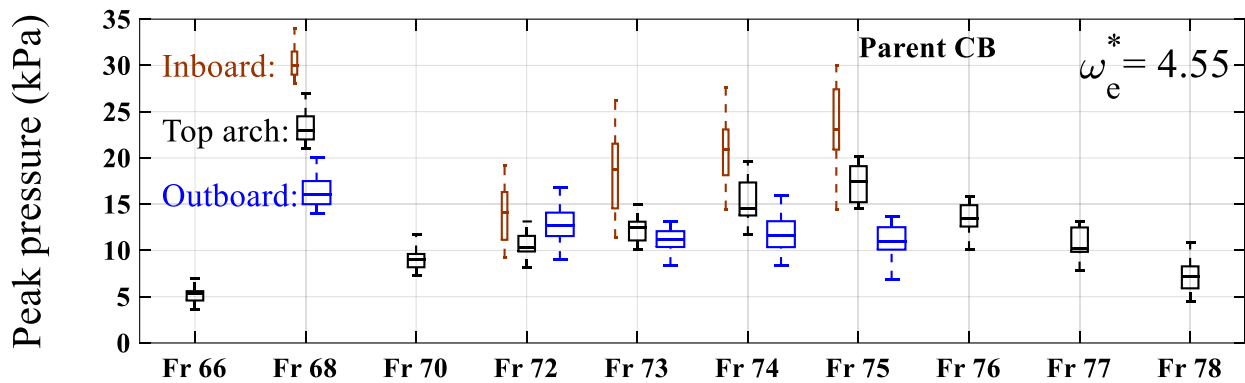

(d)

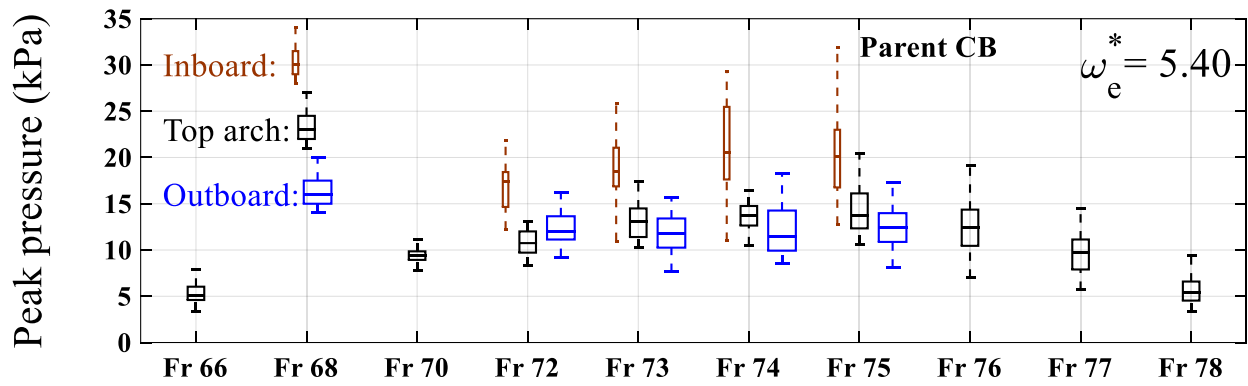

(e)

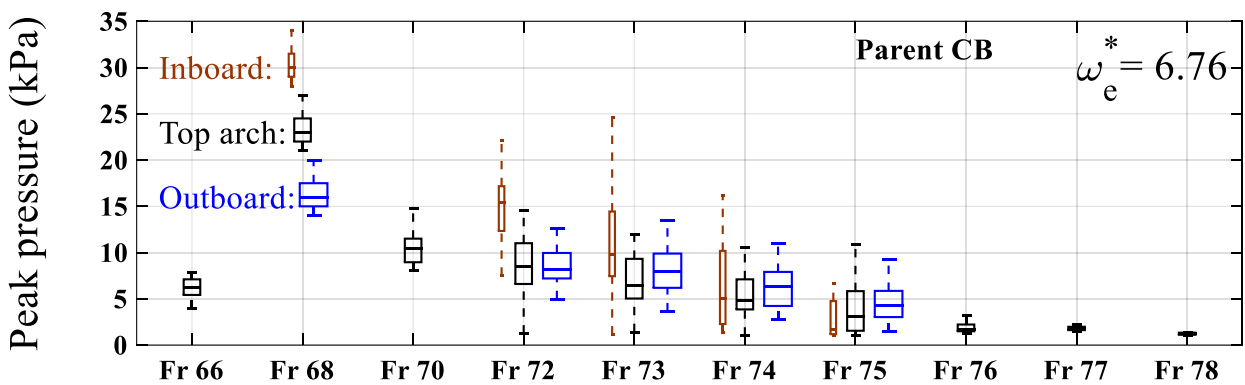

Figure 16 Sample peak pressures obtained for the Parent CB in $90 \mathrm{~mm}$ waves at $2.89 \mathrm{~m} / \mathrm{s}$ model speed for a selection of encounter wave frequencies in the range $3.51 \leq \omega_{e}^{*} \leq 6.76$, for various pressure transducers located at Fr66 to Fr78. Refer to Figure 7 for the longitudinal and transverse locations of transducers at Inboard, Top arch and Outboard. 


\section{The effect of the centre bow length on peak pressures and slam loads}

The variation of pressure distributions with $\mathrm{CB}$ length is a key consideration for CB design. It is clear from Figure 16 that the location of the maximum pressure peak varies with the encounter wave frequency. At $\omega_{\mathrm{e}}^{*}=3.51$ the maximum pressure is at frame 72, only slightly forward of the Parent CB truncation, shifting to frame 75 (the midsection of the archways) at $\omega_{\mathrm{e}}^{*}=4.55$, the frequency of maximum slam loads [1]. The medians of peak pressures appear to be higher at this frequency. As the frequency increases further the maximum pressure location tends to shift aft again, back toward the CB truncation.

At all frequencies the transverse distributions show an increase in slam pressure from outboard to inboard. This pattern is quite consistent at different longitudinal positions and wave encounter frequencies, exemplifying the influence of archway geometry on the magnitude of the peak slam pressures. The pattern is also broadly consistent amongst various CBs tested, as presented in Figures 17 and 18, showing the variations of peak pressures for different bow geometries at approximately $\omega_{e}^{*}=4.5$ and $\omega_{e}^{*}=6.3$, respectively, in $90 \mathrm{~mm}$ waves. However, the peak pressures are relatively higher for the Long CB (especially from Fr 66 to 73), and lower for the Short CB (especially for the inboard positions), than the Parent CB. It is worth noting that the drop tests of Swidan et al. [11, 12] showed that the impact pressures at various longitudinal positions is proportional to squared impact velocity, and is strongly location dependent. They also found that the magnitude of peak pressure decreased from the bow truncation (located between Fr 70 and Fr72) to the bow. Such drop tests are consistent only with the test shown in Figure 16(e), which represents slamming at $\omega_{\mathrm{e}}^{*}=6.76$ when the heave and pitch of the catamaran model are minimal [31].

From these results, it can be concluded that the maximum pressures occur forward of the CB truncation except for the Short CB. The location of the maximum pressure for different CB configurations also shows a shift aftwards when the dimensionless encounter frequency increases from $\omega_{e}^{*}=4.5$ to $\omega_{e}^{*}=6.3$, consistent with results reported in $[14,35,36]$, which showed that increases in wave frequency caused the resultant force to move aft.

In a study by Whelan [47], it was found, through two dimensional drop tests of different arch cross sections, that moving the arch top outboard was somehow beneficial for slamming pressure reductions. However, as can be seen the strongest peak pressures occur at inboard positions regardless of the CB length. This similarity in the transverse location of maximum pressure is due to the cross-sectional geometrical similarity amongst the various CB configurations. For this model, the results suggest that arch closure occurs slightly inboard of the arch top. Therefore, one possible option for reduction of the slamming pressure for each CB configuration would be to alter the inboard sectional design. 
(a)

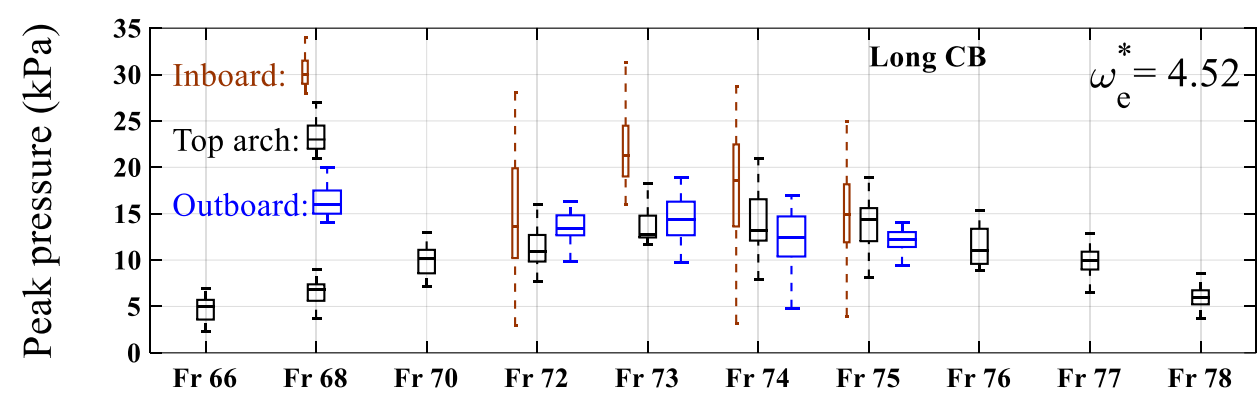

(b)
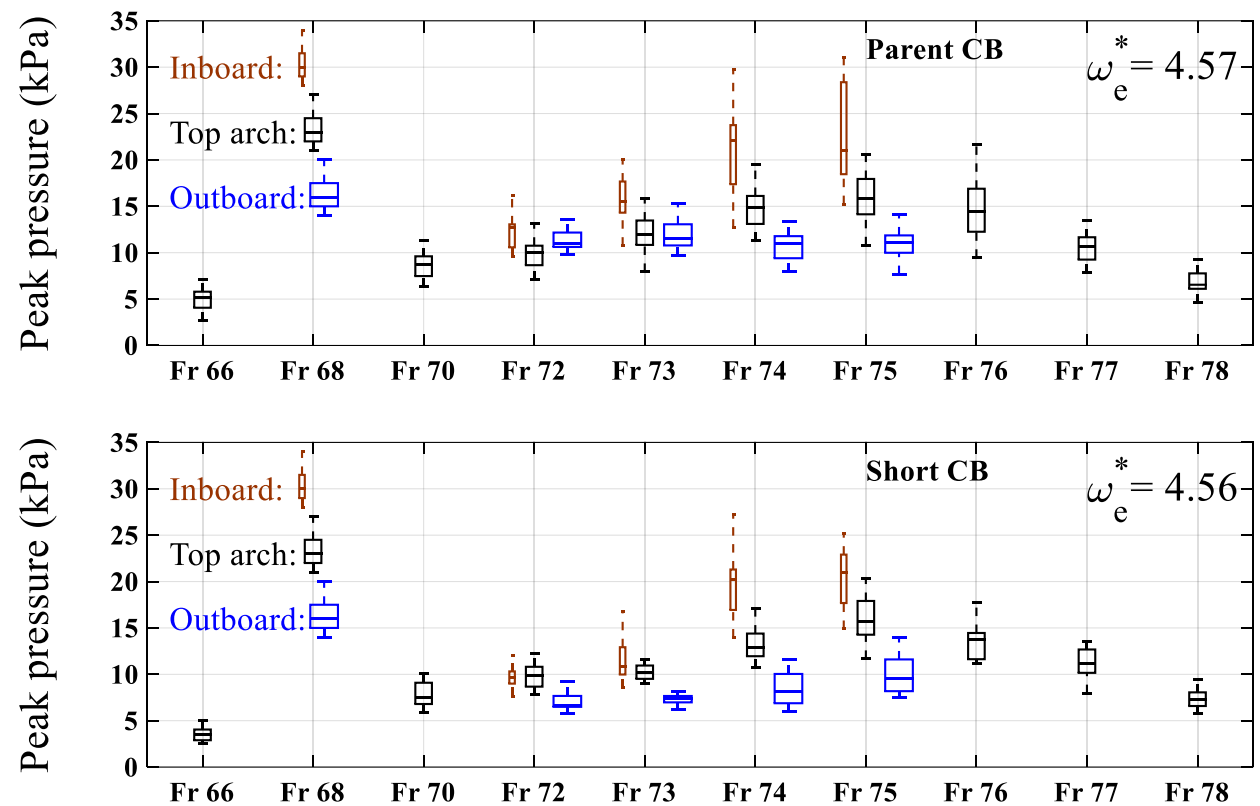

Figure 17 Sample peak pressures obtained for different CB configurations in $90 \mathrm{~mm}$ waves at $2.89 \mathrm{~m} / \mathrm{s} \mathrm{model} \mathrm{speed} \mathrm{for}$ dimensionless encounter wave frequency of $\omega_{e}^{*} \cong$ 4. 5. (a) Long CB, (b) Parent CB, (c) Short CB. Refer to Figure 7 for the longitudinal and transverse locations of transducers at Inboard, Top arch and Outboard. 
(a)

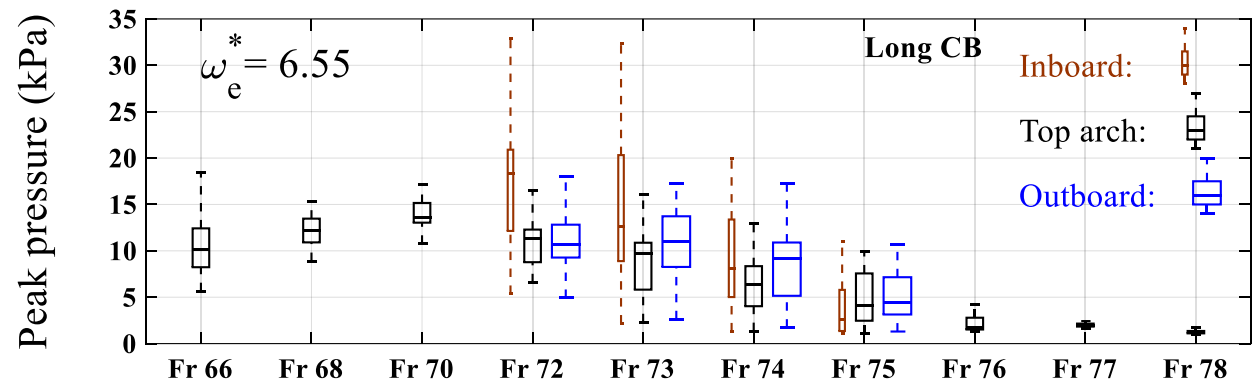

(b)

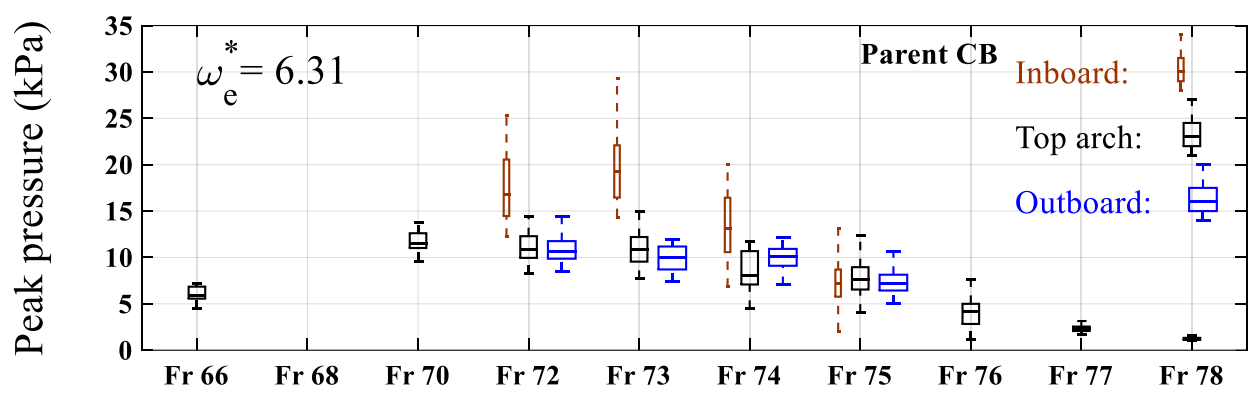

(c)

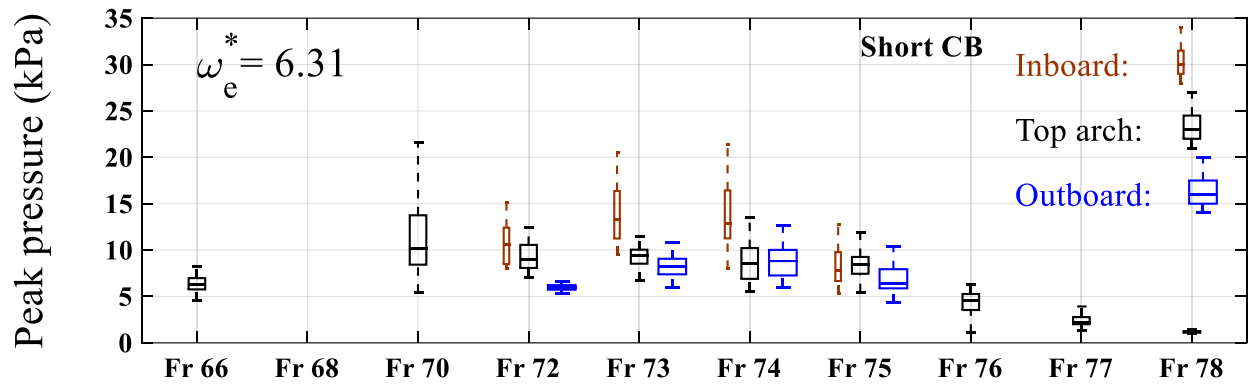

Figure 18 Sample peak pressures obtained for different CB configurations in $90 \mathrm{~mm}$ waves at $2.89 \mathrm{~m} / \mathrm{s} \mathrm{model} \mathrm{speed} \mathrm{for}$ dimensionless encounter wave frequency of $\omega_{e}^{*}>$ 6. (a)Long CB, (b) Parent CB, (c) Short CB. Refer to Figure 7 for the longitudinal and transverse locations of transducers at Inboard, Top arch and Outboard.

The histograms in Figure 19 provide an overview of the peak pressures measured for different bow configurations in nominal 60 and $90 \mathrm{~mm}$ waves at $2.89 \mathrm{~m} / \mathrm{s}$ for unique wave encounter frequencies in the range between $\omega_{\mathrm{e}}^{*}=$ 3.4 and $\omega_{\mathrm{e}}^{*}=6.6$. Note that the measured wave heights differed slightly from the nominal values; Table 5 compares the averages and standard deviations of measured versus nominal wave heights for each test condition. To calculate the histograms of Figure 19, all peak pressures recorded for different slams in a single run were identified for each transducer located at Fr 72, 73, 74 and 75 (i.e. 3 transducers at each frame). The process was repeated at each test condition and for various CB configurations. The probability density in Figure 19 is evaluated as the number of peak pressure samples in bins of width $1 \mathrm{kPa}$ as a proportion of the total number of peak pressure samples obtained from multiple tests at different wave frequencies for the given CB configuration.

The maximum pressure measured for each CB configuration could be subject to the transducer amplifier gain setting. The peak recorded values were up to $50 \mathrm{kPa}$, or around $15 \%$ of the gauge capacity of $50 \mathrm{psi}(345 \mathrm{kPa})$, but could be higher in a couple of cases because the system saturated at the gain setting used. The 50 psi gauges were however appropriate. Note that the total numbers of slamming pressures used in the histograms are not equal as it is a function of the number of slamming events considered in each case, and thus the frequency of slamming pressure cannot be compared across the given histograms. Table 5 shows the number of runs and peak slamming 
pressures used for each histogram. The number of selected peak pressures used for each histogram varied between 1800 and 3200 data points depending on test condition.

As can be seen in Figure 19, the range of peak pressures experienced by the three CBs were similar, but the density of high peak pressures increased with the increase in the wave height; therefore, the peak slamming pressures were far more influenced by the wave height than by the CB configuration. However, this is not the case when considering resultant slam forces, as discussed in section 3.2. The peak pressure with most probable intensity, as a function of wave height and centre bow configuration, was almost consistent across the parent and long CBs while it reduced slightly for the short. Overall, the histograms show that the majority of peak pressures were below 10 and $15 \mathrm{kPa}$ in 60 and $90 \mathrm{~mm}$ waves respectively, while the high peak pressures were slightly greater than $30 \mathrm{kPa}$.

It should be noted that a few high peak pressures identified as outliers in each runs were omitted. This is because the very high peak pressures may not be practically useful in terms of the ship structural design when hydroelasticity is important [42-45], and a rational evaluation of measured peak pressures is necessary prior to estimation of wave impact pressures for structural design purposes [46]. Consideration should also be made for the effect of the $\mathrm{CB}$ structural vibrations on the measured peak values because these vibrations have very high frequency and can affect the peak pressure measurements.

The scaling of the slamming pressures may be affected by the inevitable differences between Reynolds, Froude, Weber and Mach numbers at model and full scale. This is significant because the peak pressure pulse occurs over a very short duration. At the peak of the slam pulse two converging jets rising up each side of the arch meet abruptly at the instant of arch closure; this generates a local transient pressure wave. The entrainment of air also affects the impact pressures and ensuing wave, and is another consideration when it comes to scaling [48, 49] . Therefore scaling laws for very short duration dynamic events within the archways should be investigated in future research. 
(a1)

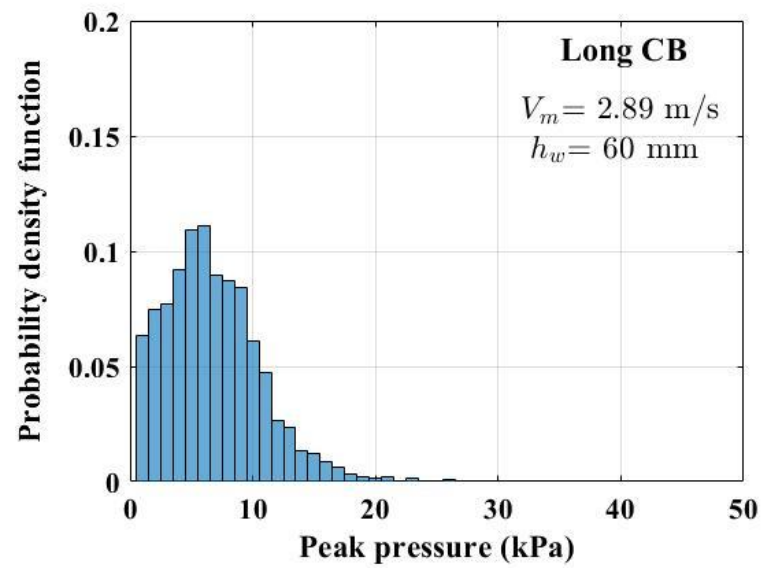

(b1)

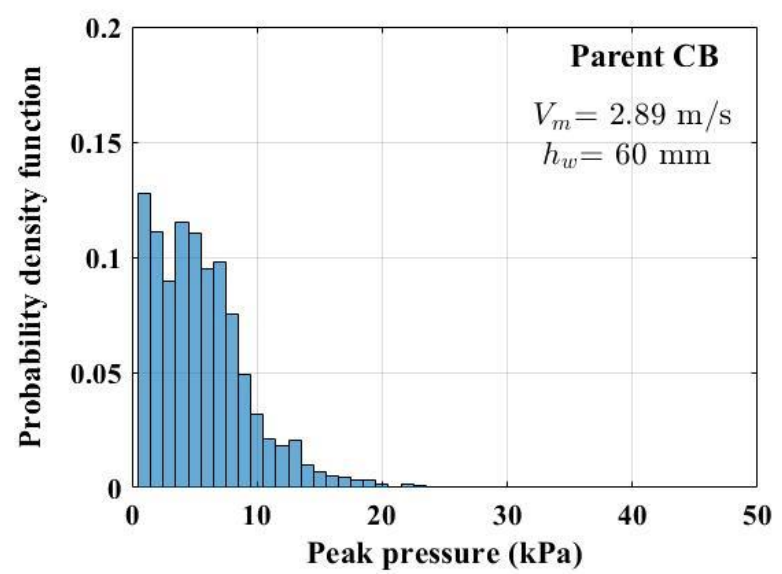

(c1)

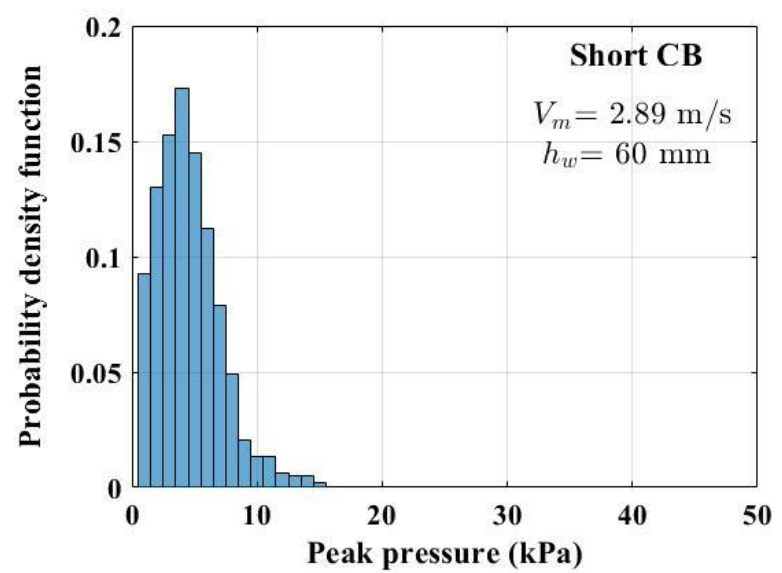

(a2)

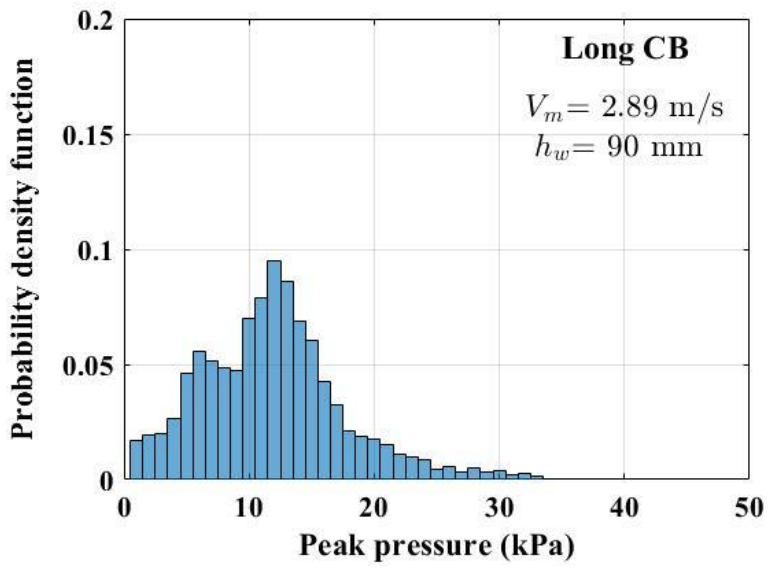

(b2)

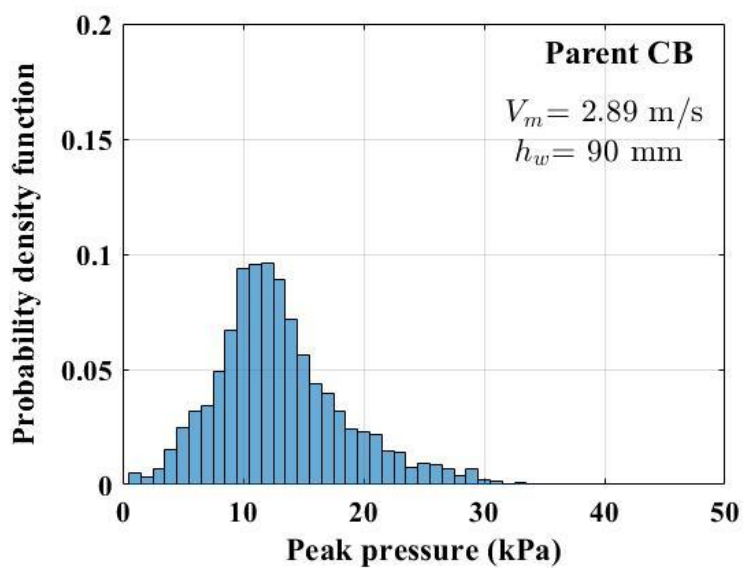

(c2)

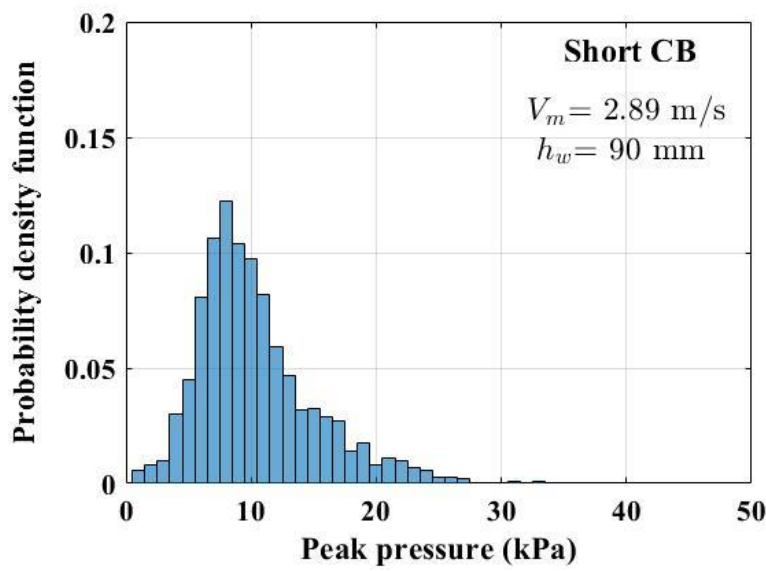

Figure 19 Comparison of the peak pressures measured using pressure transducers at 12 locations at $\mathrm{Fr} 72,73,74$ and 75 obtained for the Long, Parent and Short CBs collected from all tests conducted in the range between $\omega_{\mathrm{e}}^{*}=3.4$ and 6.6 at 60 and $90 \mathrm{~mm}$ waves at a speed of $2.89 \mathrm{~m} / \mathrm{s}$. (a1) Long CB, $h_{w}=60 \mathrm{~mm}$, (a2) Long CB, $h_{w}=90 \mathrm{~mm}$, (b1) Parent CB, $h_{w}=60 \mathrm{~mm}$, (b2) Parent CB, $h_{w}=90 \mathrm{~mm}$, (c1) Short CB, $h_{w}=60 \mathrm{~mm},(c 2)$ Short CB, $h_{w}=90 \mathrm{~mm}$. Refer to Table 5 for more details for each histogram. 
Table 5 Details in relation to peak pressure histograms shown in Figure 19

Long CB

Parent CB

Short CB

\begin{tabular}{|c|c|c|c|c|c|c|c|}
\hline Nominal wave height (mm) & & 60.0 & 90.0 & 60.0 & 90.0 & 60.0 & 90.0 \\
\hline & $\begin{array}{l}\text { Average wave } \\
\text { height }(\mathrm{mm})\end{array}$ & 58.0 & 90.4 & 61.9 & 87.9 & 58.0 & 89.7 \\
\hline Treasure vare statistics & $\begin{array}{l}\text { Standard } \\
\text { deviation }(\mathrm{mm})\end{array}$ & 2.9 & 3.6 & 1.8 & 2.7 & 3.5 & 3.6 \\
\hline $\begin{array}{l}\text { Selected range of dimensionless } \\
\text { wave encounter frequency }\end{array}$ & & \multicolumn{6}{|c|}{$3.4-6.6$} \\
\hline $\begin{array}{l}\text { Locations of and the number of } \\
\text { selected pressure transducers }\end{array}$ & & \multicolumn{6}{|c|}{$\begin{array}{c}12 \text { transducers located at Fr 72, Fr73, Fr74, Fr } 75 \\
\text { (Inboard, Outboard, Arch top) }\end{array}$} \\
\hline Number of selected runs & & 9 & 12 & 12 & 11 & 10 & 10 \\
\hline $\begin{array}{l}\text { Total number of peak pressures } \\
\text { used for each histogram }\end{array}$ & & 2354 & 3198 & 2270 & 2277 & 1805 & 1990 \\
\hline
\end{tabular}

\section{Conclusion}

The effects of CB length on slamming loads and pressures for a wave piercing catamaran were investigated using a 2.5 m hydroelastic segmented catamaran model in regular head-sea waves. Three CB length were tested that represented $18 \%, 24 \%$ and $30 \%$ of the overall model length.

Slamming pressures were measured by 18 pressure transducers. The slamming pressure pulse width (i.e. the period between the rise and falling times) was about $3 \mathrm{~ms}$, which was only about one-seventh of the corresponding slam force pulse width and $1 / 25^{\text {th }}$ of the overall period of the pressure pulse (i.e. from the start of rising time to the end of falling time). Very few slamming pressures were measured above $30 \mathrm{kPa}$, whereas the majority of slamming pressures were below $15 \mathrm{kPa}$, decreasing with the decrease of the wave height. The extreme slamming loads were in the range 75-330 $\mathrm{N}$ and depended on the wave height and CB length.

The results showed that the CB length influenced strongly slamming forces but it only slightly affected slamming pressures. The slam loads per CB length also increased as the CB length increased. This suggests that the increase or reduction in slam force is, to some degree, attributed to the increase or reduction of the effective impact area within the archways. Since the effect of the centre bow length on slamming pressures is minimal, the centre bow local panels may be designed similarly for various bow length.

The longitudinal location of maximum pressures along the $\mathrm{CB}$ was strongly related to the encounter wave frequency. At encounter wave frequencies corresponding to strong slamming pressures (in the range $\omega_{e}^{*}=$ 4.4-4.7) the location of maximum pressures was in the mid-archway region (i.e. longitudinally half way between 
the jaws and CB truncation), whereas at higher wave encounter frequencies this location was closer to the CB truncation. This is because the catamaran model had minimal motions in short waves compared to long waves. The lateral distribution of the peak pressures within the CB archways showed that the peak pressure increases from the outboard to inboard.

Overall, it was seen that the Short CB was the best design for the alleviation of slam loads while the Long CB was the least performing design. The slamming loads identified in the current study for Long, Parent and Short CBs can have a direct implication for optimal CB design as it is clear that the length of the CB is an important factor for global structural design considering slam-induced bending moments. However, the optimum CB length should also consider the $\mathrm{CB}$ buoyancy in waves, i.e. the CB entry force. It is recommended that tests be conducted in various headings, and to investigate how CB geometry could be modified to reduce the contribution of lateral jet flow to arch filling and slamming by introducing some novel designs. Further investigation is also recommended regarding the scaling of slamming loads and pressures from model scale to full-scale equivalent and should be compared with empirical approaches given in the relevant class rules. Full scale implications require further investigation in random seas as it presents a more realistic situation with authentic slamming distributions. Since irregular waves can be steeper than regular waves, in some parts, slamming kinematics can differ to that observed in regular waves, and thus investigations on slamming kinematics and probability in random waves are recommended.

\section{Acknowledgements}

This work was undertaken in collaboration between the University of Tasmania, Revolution Design and Incat Tasmania through the support of the Australian Research Council Linkage Grant number LP0883540. The work of Dr Jalal Rafie Shahraki in the development and production of the hydroelastic segmented model is also gratefully acknowledged.

\section{References}

[1] Lavroff J, Davis MR. Slamming kinematics, impulse and energy transfer for wave-piercing catamarans. Journal of Ship Research. 2015;59:145-61.

[2] Amin W, Davis MR, Thomas GA, Holloway DS. Analysis of wave slam induced hull vibrations using continuous wavelet transforms. Ocean Engineering. 2012;58:154-66.

[3] Thomas GA, Davis MR, Holloway DS, Roberts T. The Vibratory Damping of Large High Speed Catamarans. Marine Structures. 2008;21:1-21.

[4] McVicar JJ, Lavroff J, Davis MR, Thomas G. Effect of slam force duration on the vibratory response of a lightweight high-speed wave-piercing catamaran. Journal of Ship Research. 2015;59:69-84.

[5] Shabani B, Holloway D, Lavroff J, Davis M, Thomas G. Systematic model tests on centre bow design for motion and slamming load alleviation in high speed catamarans. 14th International Conference on Fast Sea Transportation2017. p. 136-43.

[6] Shahraki JR, Davis MR, Shabani B, AlaviMehr J, Thomas GA, Lavroff J, et al. Mitigation of slamming of large wave-piercing catamarans. The 30th Symposium on Naval Hydrodynamics. Hobart, Tasmania2016. p. 1-13. 
[7] Rafie Shahraki J, Thomas GA, Penesis I, Amin WAI, Davis MR, Davidson G. Centrebow design for wave-piercing catamarans. 12th International Conference on Fast Sea Transportation. Amsterdam: MCI Amsterdam - Eurocongress International v.o.f.; 2014. p. 1-8.

[8] Kapsenberg GK. Slamming of ships: where are we now? Philosophical transactions Series A, Mathematical, physical, and engineering sciences. 2011;369:2892-919.

[9] Hirdaris S, Bai W, Dessi D, Ergin Ae, Gu X, Hermundstad O, et al. Loads for use in the design of ships and offshore structures. Ocean engineering. 2014;78:131-74.

[10] Davis MR, Whelan JR. Computation of wet deck bow slam loads for catamaran arched cross sections. Ocean Engineering. 2007;34:2265-76.

[11] Swidan A, Thomas G, Penesis I, Ranmuthugala D, Amin W, Allen T, et al. Wetdeck slamming loads on a developed catamaran hullform - experimental investigation. Ships and Offshore Structures. 2016;12:653-61.

[12] Swidan A, Thomas G, Ranmuthugala D, Amin W, Penesis I, Allen T, et al. Experimental drop test investigation into wetdeck slamming loads on a generic catamaran hullform. Ocean Engineering. 2016;117:143-53.

[13] Lavroff J, Davis MR, Holloway DS, Thomas G. Determination of wave slamming loads on high-speed catamarans by hydroelastic segmented model experiments. International Journal of Maritime Engineering. 2011;153:185-97.

[14] Lavroff J, Davis MR, Holloway DS, Thomas G. Wave slamming loads on wave-piercer catamarans operating at high-speed determined by hydro-elastic segmented model experiments. Marine Structures. 2013;33:120-42.

[15] Lavroff J, Davis MR, Holloway DS, Thomas GA. The Vibratory Response of High-Speed Catamarans to Slamming Investigated by Hydroelastic Segmented Model Experiments. International Journal of Maritime Engineering. 2009;151:1-13.

[16] Lavroff J, Davis MR, Holloway DS, Thomas GA, McVicar JJ. Wave impact loads on wave-piercing catamarans. Ocean Engineering. 2017;131:263-71.

[17] Thomas G, Winkler S, Davis M, Holloway D, Matsubara S, Lavroff J, et al. Slam events of high-speed catamarans in irregular waves. Journal of Marine Science and Technology. 2011;16:8-21.

[18] Jacobi G, Thomas GA, Davis MR, Davidson G. An insight into the slamming behaviour of large high-speed catamarans through full-scale measurements. Journal of Marine Science and Technology. 2013;19:15-32.

[19] Thomas G, Davis M, Holloway D, Watson N, Roberts T. Slamming response of a large high-speed wave-piercer catamaran. Marine Technology. 2003;40:126-40.

[20] McVicar J, Lavroff J, Davis MR, Davidson G. Transient slam load estimation by RANSE simulation and by dynamic modeling of a hydroelastic segmented model. The 30th Symposium on Naval Hydrodynamics. Hobart, Tasmania2014. p. 1-16.

[21] Swidan AA, Thomas GA, Amin W, Ranmuthugala D, Penesis I. Numerical investigation of water slamming loads on wave-piercing catamaran hull model. 10th High speed marine vehicles Symposium2014. p. 1-9.

[22] Aarsnes J. Experimental techniques for local and global hydroelastic effect on ship. Seminar on Hydroelasticity in Marine Technology, Trondheim, Norway1996.

[23] Iijima K, Hermundstad O, Zhu S, Moan T. Symmetric and antisymmetric vibrations of a hydroelastically scaled model. Proceedings of the 5th International Conference on Hydroelasticity in Marine Technology2009.

[24] Dessi D, Mariani R, Coppotelli G. Experimental investigation of the bending vibrations of a fast vessel. Australian Journal of Mechanical Engineering. 2007;4:125-43.

[25] Dessi D, Mariani R, Coppottelli G, Rimondi M. Experimental identification of wet bending modes with segmented model tests. 8th International Conference on Fast Sea Transportation, FAST. Saint-Petersburg, Russia2005.

[26] Dessi D, Mariani R, La Gala F, Benedetti L. Experimental analysis of the wave induced response of a fast monohull via a segmented hull model. FAST 2003 conference. Ischia -Italy2003. p. 75-82.

[27] Hermundstad OA, Moan T. Numerical and experimental analysis of bow flare slamming on a Ro-Ro vessel in regular oblique waves. Journal of Marine Science and Technology. 2005;10:105-22.

[28] Drummen I, Storhaug G, Moan T. Experimental and numerical investigation of fatigue damage due to wave-induced vibrations in a containership in head seas. Journal of Marine Science and Technology. 2008;13:428-45.

[29] Rousset J, Ferrant P, Alessandrini B. Experiments on a segmented ship model in directional irregular waves. Proceedings of the 21th International Workshop on Water Waves \& Floating Bodies. Nantes, France2010.

[30] French BJ, Thomas GA, Davis MR. Slam occurrences and loads of a high-speed wave piercer catamaran in irregular seas. Institution of Mechanical Engineers Proceedings Part M: Journal of Engineering for the Maritime Environment. 2013:1-13.

[31] Shabani B, Lavroff J, Holloway DS, Davis MR, Thomas GA. The influence of the centre bow and wet-deck geometry on motions of wave-piercing catamarans. Proceedings of the Institution of Mechanical Engineers, Part M: Journal of Engineering for the Maritime Environment. 2017:1475090217753761.

[32] AlaviMehr J, Lavroff J, Davis MR, Holloway DS, Thomas GA. An experimental investigation of ride control algorithms for highspeed catamarans Part 1: Reduction of ship motions. Journal of Ship Research. 2017;61:35-49.

[33] AlaviMehr J, Lavroff J, Davis MR, Holloway DS, Thomas GA. An Experimental Investigation of Ride Control Algorithms for High-Speed Catamarans Part 2: Mitigation of Wave Impact Loads. Journal of Ship Research. 2017;61:51-63.

[34] Davis MR, French BJ, Thomas GA. Wave slam on wave piercing catamarans in random head seas. Ocean Engineering. 2017;135:84-97.

[35] Rafie Shahraki J. The influence of hull form on the slamming behaviour of large high speed catamarans: PhD Thesis, University of Tasmania; 2014.

[36] Lavroff J. The Slamming and Whipping Vibratory Response of a Hydroelastic Segmented Catamaran Model: PhD Thesis, University of Tasmania; 2009.

[37] DNV. Sloshing analysis of LNG membrane tanks. Classification notes Det Norske Veritas 2014.

[38] French BJ. Slamming of large high-speed catamarans in irregular seas: PhD Thesis, University of Tasmania; 2012.

[39] Amin W. Non-linear unsteady wave loads on large high-speed wave piercing catamarans: PhD Thesis, University of Tasmania; 2009. [40] Shabani B, Lavroff J, Holloway DS, Davis MR, Thomas GA. The effect of centre bow and wet-deck geometry on wet-deck slamming loads and vertical bending moments of wave-piercing catamarans. Ocean Engineering. 2018;169:401-17. 
[41] Shabani B, Lavroff J, Davis MR, Holloway DS, Thomas GA. Slam loads and kinematics of wave-piercing catamarans during bow entry events in head seas. Journal of Ship Research. 2018;62:134-55.

[42] Faltinsen OM. Hydroelastic slamming. Journal of Marine Science and Technology. 2000;5:49-65.

[43] Chen X-j, Wu Y-s, Cui W-c, Jensen JJ. Review of hydroelasticity theories for global response of marine structures. Ocean Engineering. 2006;33:439-57.

[44] Faltinsen OM, Landrini M, Greco M. Slamming in marine applications. Journal of Engineering Mathematics. 2004;48:187-217.

[45] Faltinsen OM. Hydrodynamics of high-speed marine vehicles: Cambridge university press; 2005.

[46] Mizoguchi S, Tanizawa K. Impact wave loads due to slamming: a review. Ship Technology Research 1996;43:139-54.

[47] Whelan J. Wetdeck slamming of high-speed catamarans with a centre bow University of Tasmania; 2004.

[48] Dinsenbacher A, Engle A. Guidelines for Hydroelastic Model Design, Testing and Analysis of Loads \& Responses. Tech. rept. NSWCCD-TR-65-2010/12. Naval Surface Warfare Center Carderock Division; 2011.

[49] Lafeber W, Bogaert H, Brosset L. Comparison of wave impact tests at large and full scale: Results from the sloshel project. The Twenty-second International Offshore and Polar Engineering Conference: International Society of Offshore and Polar Engineers; 2012.

39

40

41

42

43

44

45

46

47

48

49

50

51

52

53

54

55

56

57

58

59

60

61

62

63

64

65

66

67

68

69

70

71

72

73

74

75

List of Figures 
Figure 1 Incat Tasmania wave piercer catamaran with above-water centre bow (http://www.incat.com.au/)

Figure 2 Schematic plan view of the $2.5 \mathrm{~m}$ segmented catamaran model (HSM02) and locations of sensors used for instrumentation. *PT:

Pressure Transducer, A: Accelerometer, LC: Load Cell, LVDT: linear variable differential transformers.

Figure 3 The $2.5 \mathrm{~m}$ catamaran model (HSM02) of the 112-m INCAT wave piercing catamaran

Figure 4 Embedded fitting plugs manufactured on the starboard side of the CB segment

Figure 5 (a) The catamaran model with the Short CB in water, (b) The catamaran model (upside down) with the Parent CB (c) Two CB

extenders which were used to make the Parent CB (left extender) and the Long CB (both extenders) from that shown in (a) for the Short CB. The

Parent CB extender is also shown in (b)

Figure 6 Locations of the outboard, arch top and inboard pressure transducers for the Parent CB

Figure 7 Longitudinal $(x)$ and transverse $(y)$ locations of the pressure transducers for different CB configurations normalised by the length $(L m)$ and half beam $(0.5 \mathrm{Bm})$ of the catamaran model. $(\mathrm{Lm}=2500 \mathrm{~mm}, \mathrm{Bm}=680 \mathrm{~mm})$

Figure 8 (a) The CB water entry, (b) formation of lateral jet flow across the demi mull bows and (c) post slam water discharge in a forward direction from archways for the Long CB in $h w=90$ and $\mathrm{Vm}=2.89 \mathrm{~m} / \mathrm{s}$ at $\omega e *=4.82$.

Figure 9 Peak load patterns at $\omega e *=4,4.5$ and 6.3 for the Parent CB at a speed of $2.89 \mathrm{~m} / \mathrm{s}$ at (a) 60 mm wave height (b) $90 \mathrm{~mm}$ wave height Figure 10 The vertical bow entry and slam forces acting on the Parent CB for a slam event at $\omega \mathrm{e} *=4.5$ at a speed of $2.89 \mathrm{~m} / \mathrm{s}$ at $90 \mathrm{~mm}$ wave height

Figure 11 The distribution of vertical slamming forces (top) and vertical slamming forces per centre bow (bottom) length identified for each CB in (a \& c) $h w=60 \mathrm{~mm}(\mathrm{~b} \& \mathrm{~d}) h w=90 \mathrm{~mm}$;

Figure 12 Pressure time records obtained at $\omega e *=4.5$ for a speed of $2.89 \mathrm{~m} / \mathrm{s}$ in $90 \mathrm{~mm}$ wave height from transducers located at different frame (Fr) locations

Figure 13 A slam pressure record illustrating the number of data points sampled at $10 \mathrm{kHz}$ for arch filling and wet-deck slamming stages.

Figure 14 Measured pressures at different longitudinal positions obtained for different times relative to a slam instant $t s=4.99 \mathrm{~s}$ at $\omega e *=4.57$

for the Parent CB in $90 \mathrm{~mm}$ waves at $2.89 \mathrm{~m} / \mathrm{s}$ model speed. (a) $\Delta t=-10 \mathrm{~ms}$, (b) $\Delta t=-8 \mathrm{~ms}$, (c) $\Delta t=-6 \mathrm{~ms}$, (d) $\Delta t=-4 \mathrm{~ms}$, (e) $\Delta t=-2$ $\mathrm{ms}$, (f) $\Delta t=0 \mathrm{~ms}$, (g) $\Delta t=2 \mathrm{~ms}$, (h) $\Delta t=4 \mathrm{~ms}$, (i) $\Delta t=6 \mathrm{~ms}$, (j) $\Delta t=8 \mathrm{~ms}$.

Figure 15 Measured CB loads and pressures at different longitudinal positions for consecutive slam instants in a single run at $\omega e *=4.57$ for the Parent CB in $90 \mathrm{~mm}$ waves at $2.89 \mathrm{~m} / \mathrm{s}$ model speed. (a) $t s=4.99 \mathrm{~s}$, (b) $t s=5.68 \mathrm{~s}$, (c) $t s=6.37 \mathrm{~s}$, (d) $t s=7.05 \mathrm{~s}$, (e) $t s=7.74 \mathrm{~s}$, (f) $t s=8.42 \mathrm{~s}$, (g) $t s=9.11 \mathrm{~s}$, (h) $t s=9.80 \mathrm{~s}$, (i) $t s=10.48 \mathrm{~s}$, (j) $t s=11.17 \mathrm{~s}$.

Figure 16 Sample peak pressures obtained for the Parent CB in $90 \mathrm{~mm}$ waves at $2.89 \mathrm{~m} / \mathrm{s}$ model speed for a selection of encounter wave frequencies in the range $3.51 \leq \omega e * \leq 6.76$, for various pressure transducers located at Fr66 to Fr78. Refer to Figure 7 for the longitudinal and transverse locations of transducers at Inboard, Top arch and Outboard.

Figure 17 Sample peak pressures obtained for different CB configurations in $90 \mathrm{~mm}$ waves at $2.89 \mathrm{~m} / \mathrm{s}$ model speed for dimensionless encounter wave frequency of $\omega e * \cong 4.5$. (a) Long CB, (b) Parent CB, (c) Short CB. Refer to Figure 7 for the longitudinal and transverse locations of transducers at Inboard, Top arch and Outboard.

Figure 18 Sample peak pressures obtained for different CB configurations in $90 \mathrm{~mm}$ waves at $2.89 \mathrm{~m} / \mathrm{s}$ model speed for dimensionless encounter wave frequency of $\omega e *>6$. (a)Long CB, (b) Parent CB, (c) Short CB. Refer to Figure 7 for the longitudinal and transverse locations of transducers at Inboard, Top arch and Outboard.

Figure 19 Comparison of the peak pressures measured using pressure transducers at 12 locations at Fr 72, 73, 74 and 75 obtained for the Long, Parent and Short CBs collected from all tests conducted in the range between $\omega$ e $*=3.4$ and 6.6 at 60 and 90 mm waves at a speed of $2.89 \mathrm{~m} / \mathrm{s}$. (a1) Long CB, hw = $60 \mathrm{~mm}$, (a2) Long CB, hw = $90 \mathrm{~mm}$, (b1) Parent CB, hw = $60 \mathrm{~mm}$, (b2) Parent CB, hw = $90 \mathrm{~mm}$, (c1) Short CB, hw = $60 \mathrm{~mm}$, (c2) Short CB, hw $=90 \mathrm{~mm}$. Refer to Table 5 for more details for each histogram.

\section{List of Tables}

Table 1 Specifications of the model and full-scale catamaran vessel

Table 2 Instruments used in HSM02 model tests

Table 3 Main characteristics of various CB configurations after construction

Table 4 Model test conditions

Table 5 Details in relation to peak pressure histograms shown in Figure 19 